\title{
Effects of Initial Drivers and Land Use on WRF Modeling for Near-Surface Fields and Atmospheric Boundary Layer over the Northeastern Tibetan Plateau
}

\author{
Junhua Yang ${ }^{1}$ and Keqin Duan ${ }^{2}$ \\ ${ }^{1}$ State Key Laboratory of Cryospheric Sciences, Cold and Arid Regions Environmental and Engineering Research Institute, \\ Chinese Academy of Sciences, Lanzhou 730000, China \\ ${ }^{2}$ College of Tourism and Environment, Shaanxi Normal University, Xian 710119, China
}

Correspondence should be addressed to Keqin Duan; kqduan@snnu.edu.cn

Received 5 July 2015; Revised 1 November 2015; Accepted 3 November 2015

Academic Editor: Enrico Ferrero

Copyright (c) 2016 J. Yang and K. Duan. This is an open access article distributed under the Creative Commons Attribution License, which permits unrestricted use, distribution, and reproduction in any medium, provided the original work is properly cited.

To improve the simulation performance of mesoscale models in the northeastern Tibetan Plateau, two reanalysis initial datasets (NCEP FNL and ERA-Interim) and two MODIS (Moderate-Resolution Imaging Spectroradiometer) land-use datasets (from 2001 and 2010) are used in WRF (Weather Research and Forecasting) modeling. The model can reproduce the variations of $2 \mathrm{~m}$ temperature (T2) and $2 \mathrm{~m}$ relative humidity ( $\mathrm{RH} 2$ ), but $\mathrm{T} 2$ is overestimated and $\mathrm{RH} 2$ is underestimated in the control experiment. After using the new initial drive and land use data, the simulation precision in T2 is improved by the correction of overestimated net energy flux at surface and the RH2 is improved due to the lower T2 and larger soil moisture. Due to systematic bias in WRF modeling for wind speed, we design another experiment that includes the Jimenez subgrid-scale orography scheme, which reduces the frequency of low wind speed and increases the frequency of high wind speed and that is more consistent with the observation. Meanwhile, the new drive and land-use data lead to lower boundary layer height and influence the potential temperature and wind speed in both the lower atmosphere and the upper layer, while the impact on water vapor mixing ratio is primarily concentrated in the lower atmosphere.

\section{Introduction}

Near-surface meteorological fields are the most important and basic elements for weather and climate research and provide crucial information for water resources, wind energy, and agricultural activities. For example, an accurate spatial and temporal description of the temperature field is essential for evaluations of water resources and ecosystems and is also an important input variable for hydrological models [1]. At the same time, because it acts as a link between land surface and free atmosphere, the atmospheric boundary layer affects regional climate via land-atmosphere coupling of momentum, energy, water, and matter $[2,3]$.

Observations and numerical simulations are the two most important methods used to acquire information from nearsurface meteorological fields and the atmospheric boundary layer structure. However, the distribution of stations is still sparse in regions with complex terrain such as the Tibetan
Plateau, and the detailed spatial distribution of meteorological fields cannot be obtained from routine stations observations, including the complex flow field caused by topographic forcing, terrain obstruction, and funneling [4]. Recently, with the development of mesoscale numerical models, the advantages of numerical simulations have been highlighted due to their ability to provide high-resolution data for near-surface meteorological fields and the atmospheric boundary layer structure. In addition, mesoscale models are commonly used to provide an in-depth understanding of the relevant physical process and mechanisms. The WRF (Weather Research and Forecasting) is a mesoscale numerical model that has been widely used since its development in 2000. Many researchers have studied the factors that affect the model performance and have found that the WRF simulation accuracy depends on spatial resolution, initial conditions, parameterization scheme, and driving data [5-8]. 
Reanalysis datasets provide initial and boundary conditions for mesoscale models, and the precision of these data directly influences the model performance. To date, few studies have focused on the impact of different driving data on WRF performance on the northeastern Tibetan Plateau, which is the headwater of many inland rivers in western arid and semiarid China. Thus, analysis of the impact of different reanalysis data on the WRF simulation of nearsurface meteorological fields and the atmospheric boundary layer structure is important for studies of land-atmosphere interaction in the region.

Additionally, the accuracy of land surface parameters, including topography, land use, vegetation cover, and soil type, also influences the modeled land surface processes and atmospheric boundary layer characteristics. These variables greatly influence the model performance and directly determine surface parameters such as albedo, emissivity, roughness, leaf area index, vegetation roots, impedance vegetation, soil porosity, and soil thermal conductivity [9]. Previous studies primarily focused on parameterization schemes for land surface models [10, 11]. Recent studies have explored the effect of land surface data on the simulation accuracy of near-surface meteorological fields through the improvement of land surface data [12-15]. In the WRF model, the default land-use information is taken from the 2001 MODIS-based land-use data, and, thus, we can investigate the possibility of improving WRF performance by applying newly acquired land-use data.

To better understand the applicability of the driving and underlying surface data for the WRF model, two reanalysis datasets (NCEP FNL and ERA-Interim) and two MODIS land-use datasets (from 2001 and 2010, resp.) were chosen to explore the possibility of improving model performance in the region. The outline of the paper is as follows. Section 2 introduces the data and methods. Sections 3 and 4 show the impacts of driving and land-use data on the nearsurface meteorological fields and atmospheric boundary layer, respectively. Thesummary and conclusions from the results are presented in Section 5.

\section{Data and Methods}

2.1. Study Area and Ground Meteorological Observation Data. The northeastern Tibetan Plateau $\left(94^{\circ} 39^{\prime}-103^{\circ} 27^{\prime}\right.$ E, $35^{\circ} 51^{\prime}-$ $40^{\circ} 31^{\prime} \mathrm{N}$ ), with an elevation range from $758 \mathrm{~m}$ to $5725 \mathrm{~m}$ a.s.l., was chosen as the study area, as shown in Figure 1(a). This area contains the headwaters of many inland rivers (e.g., the Heihe and Sule rivers) and plays an important role in the hydrology and agriculture of the downstream arid region. A total of 34 meteorological stations are located in the study area, and these stations provide daily observations of the 2 $\mathrm{m}$ temperature, $2 \mathrm{~m}$ relative humidity, and $10 \mathrm{~m}$ wind speed. Among these stations, Arou station is located in the Heihe River watershed with an elevation of $3033 \mathrm{~m}$. The observation systems at this station include a meteorological tower used to measure the gradients of meteorological variables such as surface temperature, humidity, wind speed, soil temperature, soil humidity, surface heat flux, and radiation flux at intervals of 10 minutes and an eddy covariance system that records
TABLE 1: Experiment designs.

\begin{tabular}{lcc}
\hline $\begin{array}{l}\text { Experiment } \\
\text { name }\end{array}$ & $\begin{array}{c}\text { Initial driving and land-use } \\
\text { data }\end{array}$ & $\begin{array}{c}\text { Subgrid-scale } \\
\text { orography }\end{array}$ \\
\hline CTRL & $\begin{array}{c}\text { NCEP and 2001 } \\
\text { MODIS-based }\end{array}$ & No scheme \\
\hline INTL & $\begin{array}{c}\text { ERA-Interim and 2001 } \\
\text { MODIS-based }\end{array}$ & No scheme \\
\hline MODS & NCEP and 2010 MODIS-based & No scheme \\
\hline INMO & $\begin{array}{c}\text { ERA-Interim and 2010 } \\
\text { MODIS-based }\end{array}$ & No scheme \\
\hline JIME & $\begin{array}{l}\text { NCEP and 2001 } \\
\text { MODIS-based }\end{array}$ & Jimenez scheme \\
\hline
\end{tabular}

sensible heat, latent heat, and soil heat flux at intervals of 30 minutes $[16,17]$. This data set was provided by "Heihe Plan Science Data Center, National Natural Science Foundation of China" (http://www.heihedata.org/).

2.2. Model Setup and Experimental Design. The numerical experiments in this study were conducted using the Advanced Research WRF model Version 3.5. The WRF is a nonhydrostatic, primitive-equation, mesoscale meteorological model with advanced dynamics, physics, and numerical schemes (details of the model can be found at http://www .mmm.ucar.edu/). In this study, the model domains are twoway nested with $24 \mathrm{~km}(103 \times 91$ grids $)$ and $8 \mathrm{~km}(118 \times 91$ grids) horizontal spacings (Figure 1(b)). Each domain contains 28 vertical pressure levels with the top level set at $50 \mathrm{hPa}$. The scope of domain d02 is consistent with the study area shown in Figure 1(a). The WRF physical parameterization schemes used in this research include the Purdue Lin microphysical parameterization, Rapid Radiative Transfer Model (RRTM) long-wave radiation scheme, Dudhia short-wave radiation scheme, Monin-Obukhov surface layer, Noah land surface, Mellor-Yamada-Janjic (MYJ) planetary boundary layer scheme, and Grell-Devenyi (GD) cumulus scheme.

The simulation period runs from 0:00 UTC 30 May 2013 to 18:00 UTC 30 June 2013, and the first 56 hours are used for model spin uptime. Additionally, during the simulation period, the grid nudging method is used to nudge the WRF run towards a gridded analysis linearly interpolated in time between specified analyses. To investigate the impact of driving and land surface data on WRF modeling in the northeastern Tibetan Plateau, a control (CTRL) experiment and three sensitivity experiments were performed in this study. As shown in Table 1, in the CTRL experiment, both the initial driving and land-use data are the defaults for the model, namely, the NCEP-NCAR Final (FNL) and the 2001 MODISbased land-use data. In the INTL experiment, the NCEP FNL data are replaced by the ERA-Interim data, whereas in the MODS experiment the 2001 MODIS-based land-use data are replaced by the 2010 MODIS-based land-use data. Finally, in the INMO experiment, both the default driving and landuse data are replaced by the ERA-Interim and 2010 MODISbased land-use data. In addition, to examine the effect of topography on wind speed and direction, we designed another experiment known as JIME, which uses the Jiménez 


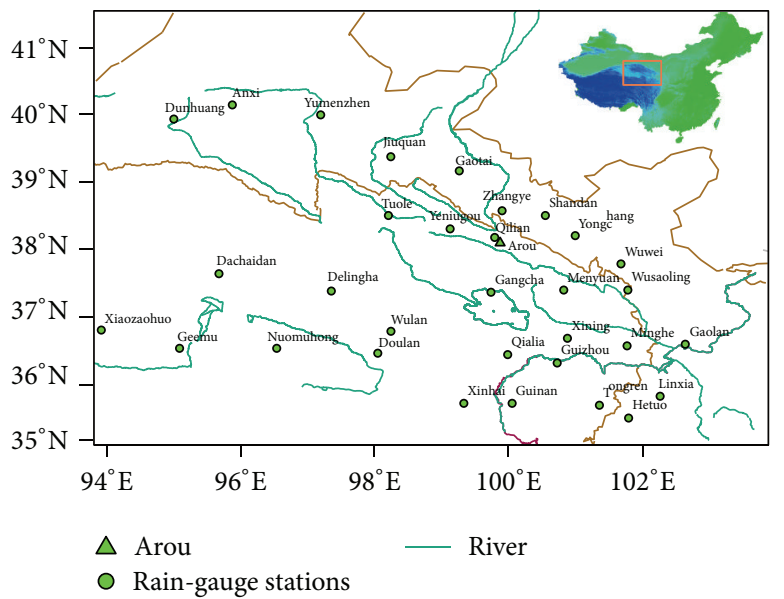

(a)

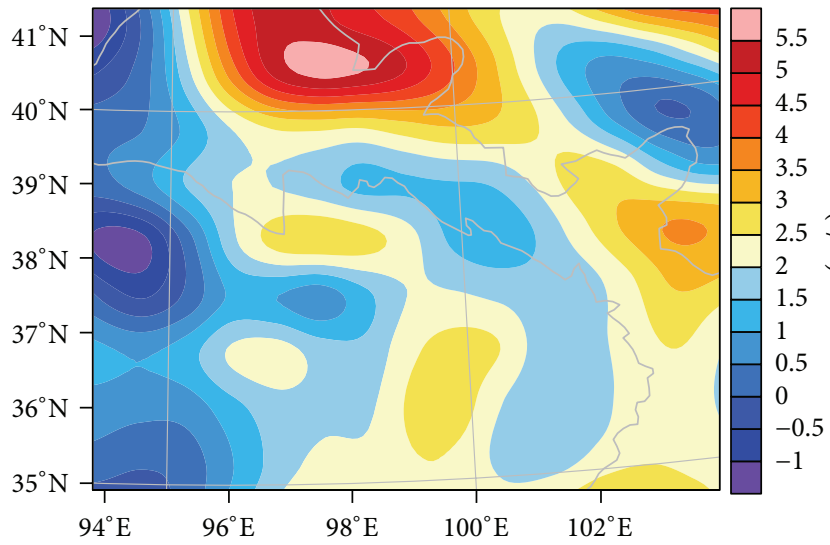

(c)

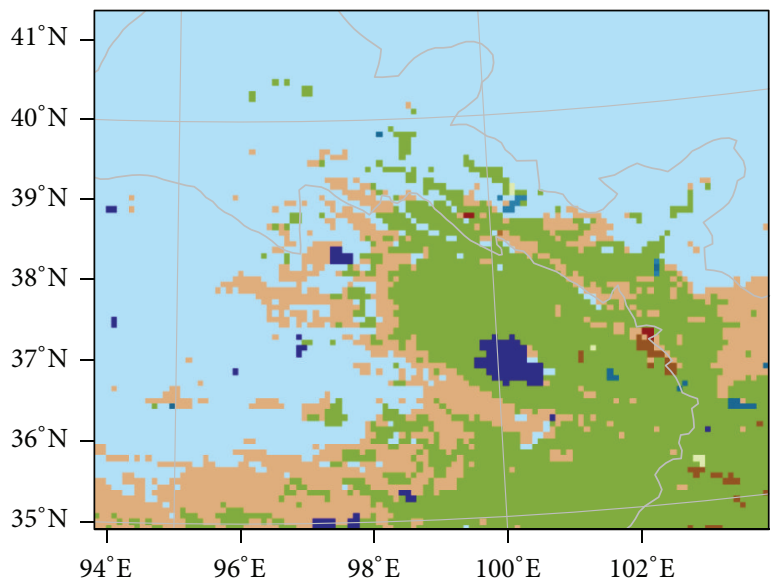

(e)

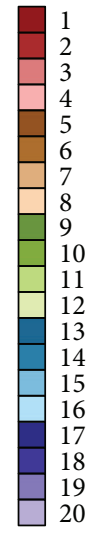

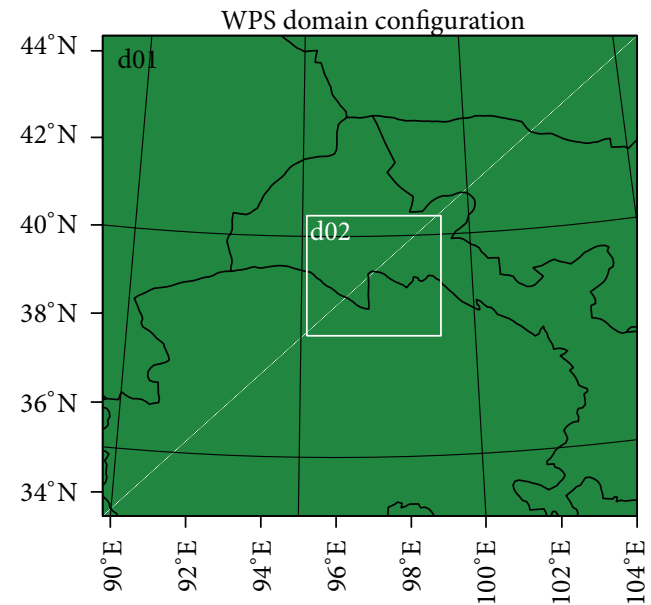

(b)

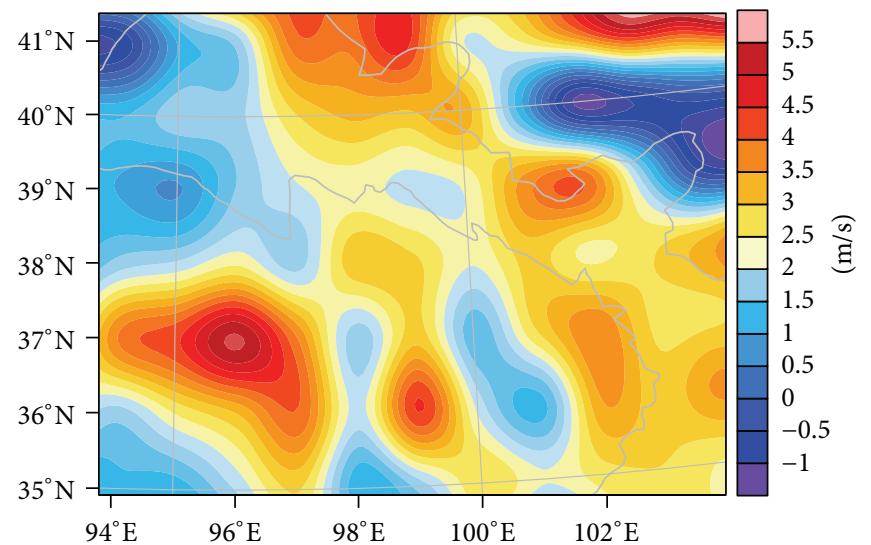

(d)

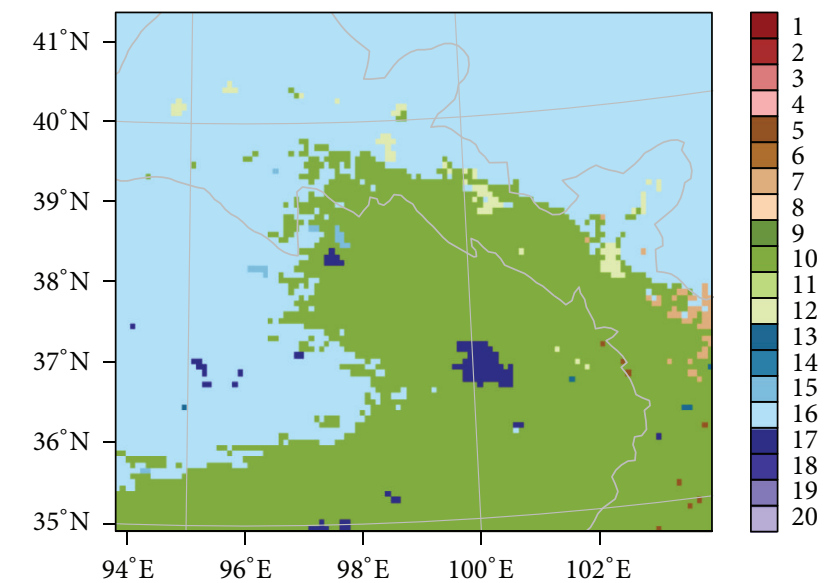

(f)

FIGURE 1: Study area, initial field, and land surface information: (a) 43 stations on northeastern Tibetan Plateau; (b) two-way nested domains in the WRF model; (c) U10 in NCEP FNL; (d) U10 in ERA-Interim; (e) MODIS-based land-use data in 2001; (f) MODIS-based land-use data in 2010. In (e) and (f), the land-use categories are as follows: 1: evergreen needleleaf forest; 2: evergreen broadleaf forest; 3: deciduous needleleaf forest; 4: deciduous broadleaf forest; 5: mixed forests; 6: closed shrublands; 7: open shrublands; 8: woody savannas; 9: savannas; 10: grasslands; 11: permanent wetlands; 12: croplands; 13: urban and built-up land; 14: cropland/natural vegetation mosaic; 15: snow and ice; 16: barren or sparsely vegetated; 17: water; 18: wooded tundra; 19: mixed tundra; and 20: barren tundra. 
[18] scheme as the subgrid-scale orography parameterization scheme compared with the CTRL experiment.

2.3. Two Types of Driving and Land-Use Data. Two types of initial driving data are used in this research. The NCEP FNL data from the Global Data Assimilation System (GDAS) have a spatial resolution of $1^{\circ} \times 1^{\circ}$ and a time interval of $6 \mathrm{~h}$. The data include ground information and a total of 26 layers $(1000 \mathrm{hPa}$ to $10 \mathrm{hPa})$ of isobaric surface data. The ERA-Interim program began in 2006 and was intended to improve and gradually displace the ERA-40. The spatial resolution of ERA-Interim reanalysis data used in this study is $0.75^{\circ} \times 0.75^{\circ}$, and the time interval is $6 \mathrm{~h}$. These data include ground information and a total of 37 layers $(1000$ to $1 \mathrm{hPa})$ of isobaric surface data. Figures $1(\mathrm{c})$ and $1(\mathrm{~d})$ show the $U$ wind speed from the NCEP FNL and ERA-Interim reanalysis data, respectively, and we note existence of large differences between the two datasets.

The default land-use data (Figure 1(e)) of the WRF model are the 2001 MODIS-based land-use data provided by Boston University. However, in recent years, the land-use types have obviously changed under the influences of climate change and human activity. Therefore, we used the year 2010 of the 16-day synthesized MODIS enhanced vegetation index (EVI) data and days 223 to 230 (no clouds phase) of the 8day synthesized surface reflectance and SRTM DEM digital elevation data to remake the land-use dataset according to the classifications of the MODIS 2001 land use. The specific steps are described as follows. First, for the EVI and surface reflectance data, we used the principal component transform to compress the amount of data and calculated the degree of homogeneity of the first principal component obtained from the reflectance data using the gray level cooccurrence matrix. Then, we constructed a classification data matrix consisting of the EVI principal component, reflectance principal component, digital elevation, and homogeneous degree information. Next, we chose typical training areas for all types of surface objects based on high-resolution Google Earth data and converted them into training samples corresponding to the MODIS data. Finally, we used the decision tree classifiers constructed by the CART algorithm to perform computer classification and obtained the new land-use classification of the study area. The 2010 MODIS-based land-use data are shown in Figure 1(f).

\section{Effects of Driving and Land-Use Data on Near-Surface Meteorological Fields}

3.1. Meteorological Field Simulation Difference. The observed daily mean $2 \mathrm{~m}$ temperature (T2), $2 \mathrm{~m}$ relative humidity (RH2), and $10 \mathrm{~m}$ wind speed (U10) values at the 34 meteorological stations are used to quantitatively evaluate the simulated results (the sample number is 1020). The scatter diagram between the observed and modeled nearsurface meteorological elements is shown in Figure 2, and the corresponding statistical analysis is presented in Table 2. For T2, the CTRL experiment has the lowest simulation precision and produces the smallest $R(0.64)$ and the largest RMSE (5.2) compared with other three experiments. The
TABLE 2: Statistics of $T 2\left({ }^{\circ} \mathrm{C}\right), \mathrm{RH} 2(\%)$, and $U 10(\mathrm{~m} / \mathrm{s})$ between the observation and model results.

\begin{tabular}{ccccccccc}
\hline & & $N$ & $C_{\mathrm{OBS}}$ & $C_{\mathrm{MOD}}$ & $R$ & $\mathrm{MB}$ & $\mathrm{NMB}(\%)$ & $\mathrm{RMSE}$ \\
\hline \multirow{4}{*}{ T2 } & CTRL & 1020 & 15.9 & 17.4 & 0.64 & 1.5 & 9.4 & 5.2 \\
& INTL & 1020 & 15.9 & 17.1 & 0.67 & 1.2 & 7.5 & 4.9 \\
& MODS & 1020 & 15.9 & 17.2 & 0.66 & 1.3 & 8.2 & 4.9 \\
& INMO & 1020 & 15.9 & 16.8 & 0.69 & 0.9 & 5.7 & 4.6 \\
\hline \multirow{6}{*}{ RH2 } & CTRL & 1020 & 49.6 & 31.5 & 0.49 & -18.1 & -36.4 & 27.4 \\
& INTL & 1020 & 49.6 & 38.6 & 0.52 & -11 & -22.1 & 22.4 \\
& MODS & 1020 & 49.6 & 36.5 & 0.51 & -13.1 & -26.4 & 23.5 \\
& INMO & 1020 & 49.6 & 39.7 & 0.55 & -9.9 & -19.9 & 20.2 \\
\hline \multirow{6}{*}{ U10 } & CTRL & 1020 & 2.9 & 2.3 & 0.12 & -0.6 & -20.7 & 1.54 \\
& INTL & 1020 & 2.9 & 2.4 & 0.13 & -0.5 & -17.2 & 1.65 \\
& MODS & 1020 & 2.9 & 2.2 & 0.10 & -0.7 & -24.1 & 2.01 \\
& INMO & 1020 & 2.9 & 2.4 & 0.12 & -0.5 & -17.2 & 1.61 \\
\hline
\end{tabular}

$N$ is the number of paired samples; $C_{\mathrm{OBS}}$ and $C_{\mathrm{MOD}}$ are the average values of observation and model results; $R$ is the correlation coefficient between the observation and model results; $\mathrm{MB}$ and $\mathrm{NMB}$ are the mean biases between the observation and model results and the normalized mean bias between the observation and model results, respectively; RMSE is the root-mean-square error of observation and model results.

highest precision occurs in INMO experiment, whose $R$ increases by 0.05 and $\mathrm{MB}$ reduces by 0.6 compared with CTRL experiment. Additionally, $R$ in INTL experiment is 0.01 larger and $\mathrm{MB}$ is $0.1 \mathrm{~K}$ smaller than those in MODS experiment. For RH2, the largest underestimation occurs in CTRL experiment $(\mathrm{MB}=-18.1)$, and the three sensitivity experiments show somewhat improvement (with MB of -11 to -9.9). Compared with CTRL experiment, $R$ increases by 0.06 and RMSE reduces by 7.2 in INMO experiment which presents the highest precision among four experiments. For wind speed, the model performance is worse than the above two meteorological parameters. The correlation coefficients between the observed and simulated values are quite low in the four experiments, and the observed mean wind speed is higher than the modeled values.

To summarize, the new initial field and underlying surface condition show improvement in modeling T2 and $\mathrm{RH} 2$, though not providing sufficient improvement in U10.

3.2. Analysis of the Improvement in Simulated Meteorological Field. In this section, we take Arou station as an example to analyze how the model improves the near-surface meteorological field simulation under the new initial condition and land-use data.

3.2.1. Surface Radiation. Figure 3 shows the time series of observed and simulated surface radiation (short wave (SW), reflected short wave (RSW), long wave (LW), and upward long ware (ULW)) in June at Arou station. The corresponding statistical analysis of the comparisons is shown in Table 3. In Figure 3(a), the modeled short-wave radiation agrees well with observations (with $R$ of 0.81 to 0.87 ), and $R$ in INTL experiment is larger than MODS experiment. Around 12:00 on June 3 (local time, all the time used in latter part is local time), the measured solar short-wave radiation decreases 

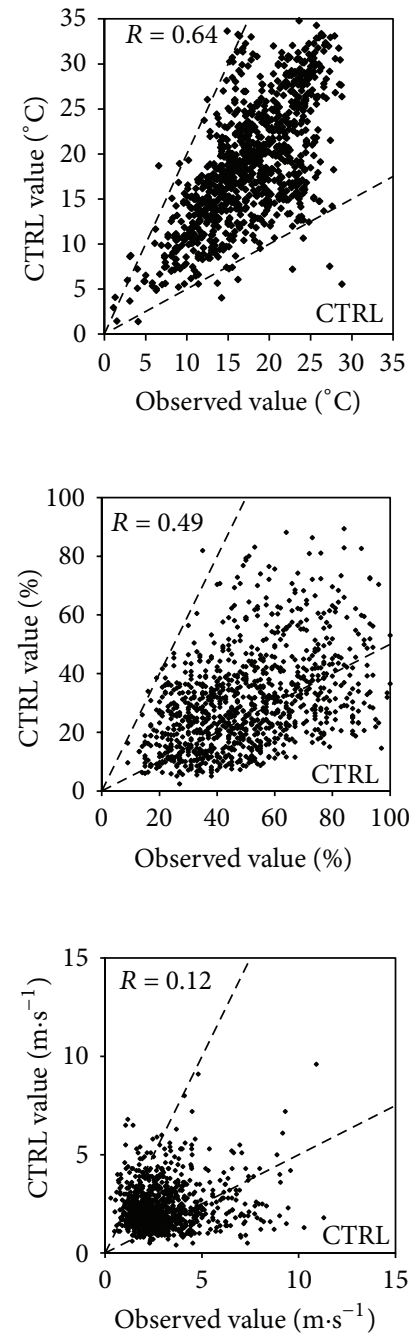
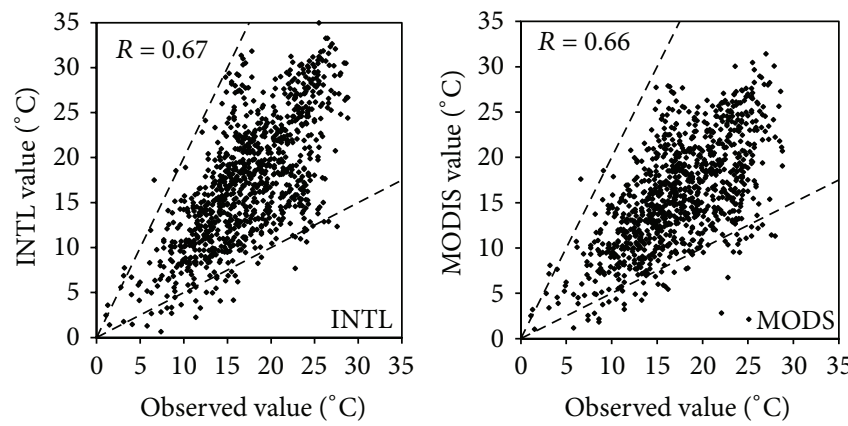

(a) $\mathrm{T} 2$
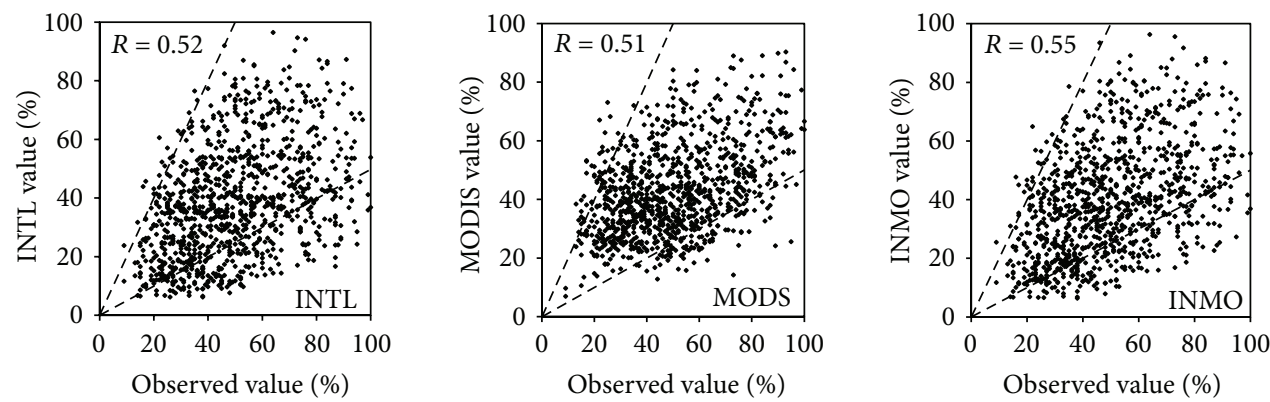

(b) $\mathrm{RH} 2$
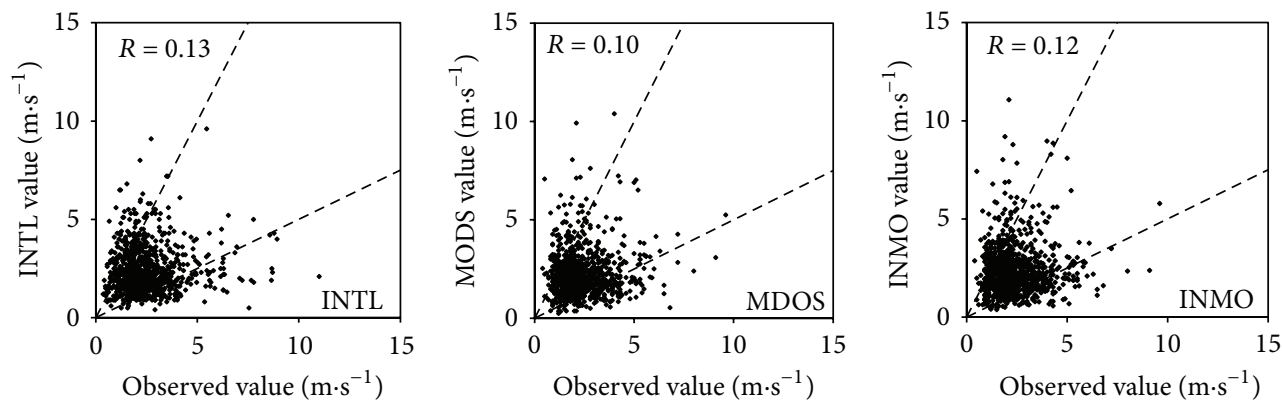

(c) U10

FIGURE 2: Scatter distribution between observed and modeled near-surface meteorological fields: (a) $2 \mathrm{~m}$ temperature (T2), (b) $2 \mathrm{~m}$ relative humidity (RH2), and (c) $10 \mathrm{~m}$ wind speed and (U10). The 1:2 and 2:1 reference lines are provided.

suddenly. This decrease might be caused by large cloud cover. The modeled SW in INTL experiment is closer to the observed values in this period, which means that the ERAInterim driving data can successfully simulate the impact of cloud cover in this day. In Figure 3(b), four experiments simulate the reflected solar radiation well, with $R$ of 0.82 to 0.89 , because the simulated albedos are rather close to the observed value (Table 4). Due to the deviation of the modeled solar short-wave radiation, the simulation values of the RSW are much higher than the observed results at noon (e.g., on June 18 and 19). In Figure 3(c), the simulated deviation in the LW is greater than that of other radiation variables, with $R$ of 0.59 to 0.62 and $\mathrm{MB}$ of -23.4 to $-20.7 \mathrm{wm}^{2}$. The underestimation of $\mathrm{LW}$ was also found in previous studies [19, 20]. In Figure 3(d), the variation in ULW is reproduced well, with $R$ of 0.82 to $0.86, \mathrm{MB}$ of 4.3 to 14.3 , and $\mathrm{NMB}$ of 1.1 to 3.8 . The MODS experiment has greater precision in simulation of ULW compared with CTRL and INTL experiments, due to lower emissivity as shown in Table 4 and the lower emissivity leads to smaller ULW.
3.2.2. Surface Energy. Solar radiation is the most fundamental source of earth-atmosphere system energy. A portion of solar radiation is used to release sensible heat and latent heat to provide energy for transportation of the turbulent boundary layer, and the other portion is absorbed by the land surface via the heat transfer processes. Figure 4 shows the comparisons between observed and modeled net radiance $(\mathrm{NR})$, sensible heat $(\mathrm{SH})$, latent heat $(\mathrm{LH})$, and soil heat flux (SHF) in the four experiments, and the corresponding statistical analysis is shown in Table 4. In Figure 4(a), the simulated NR agrees well with the observed values, with $R$ of 0.84 to 0.87 . However, on several days (e.g., June 2 at noon), the NR are larger than the measurements because of the overestimation of the solar short-wave radiation. In Figure 4(b), the variation tendency of the modeled SH is relatively consistent with the observations (with $R$ of 0.74 to 0.77 ), and the negative values are simulated in all experiments (low-level inversion structure). However, the $\mathrm{SH}$ is significantly overestimated $(\mathrm{MB}=43.6,34.9,38.6$, and 32.4, resp.), especially in the CTRL experiment where the largest 
TABLE 3: Statistics of surface radiation (SW $\left(\mathrm{wm}^{2}\right), \mathrm{RSW}\left(\mathrm{wm}^{2}\right), \mathrm{LW}$ $\left(\mathrm{wm}^{2}\right)$, and ULW $\left.\left(\mathrm{wm}^{2}\right)\right)$, surface energy $\left(\mathrm{NR}\left(\mathrm{wm}^{2}\right), \mathrm{SH}\left(\mathrm{wm}^{2}\right)\right.$, $\mathrm{LH}\left(\mathrm{wm}^{2}\right)$, and SHF $\left(\mathrm{wm}^{2}\right)$ ), and soil temperature and moisture (ST $\left({ }^{\circ} \mathrm{C}\right)$ and $\left.\mathrm{SM}\left(\mathrm{m}^{3} \mathrm{~m}^{-3}\right)\right)$ between the observation and model results at Arou station.

\begin{tabular}{|c|c|c|c|c|c|c|c|c|}
\hline & & $N$ & $C_{\mathrm{OBS}}$ & $C_{\mathrm{MOD}}$ & $R$ & MB & NMB (\%) & RMSE \\
\hline \multirow{4}{*}{ SW } & CTRL & 238 & 248.3 & 309.2 & 0.81 & 60.9 & 24.4 & 176.4 \\
\hline & INTL & 238 & 248.3 & 297.6 & 0.86 & 49.3 & 19.8 & 167.0 \\
\hline & MODS & 238 & 248.3 & 302.1 & 0.84 & 50.8 & 20.4 & 169.4 \\
\hline & INMO & 238 & 248.3 & 294.2 & 0.87 & 45.9 & 18.5 & 160.4 \\
\hline \multirow{4}{*}{ RSW } & CTRL & 238 & 54.2 & 65.6 & 0.82 & 11.4 & 21.0 & 45.5 \\
\hline & INTL & 238 & 54.2 & 63.7 & 0.87 & 9.5 & 17.5 & 43.7 \\
\hline & MODS & 238 & 54.2 & 65.2 & 0.84 & 11 & 20.2 & 46.8 \\
\hline & INMO & 238 & 54.2 & 63.5 & 0.89 & 9.3 & 17.2 & 42.5 \\
\hline \multirow{4}{*}{ LW } & CTRL & 238 & 310.8 & 287.4 & 0.59 & -23.4 & -7.5 & 40.8 \\
\hline & INTL & 238 & 310.8 & 288.5 & 0.61 & -22.3 & -7.2 & 38.1 \\
\hline & MODS & 238 & 310.8 & 289.0 & 0.61 & -21.8 & -7.0 & 38.8 \\
\hline & INMO & 238 & 310.8 & 290.1 & 0.62 & -20.7 & -6.6 & 38.0 \\
\hline \multirow{4}{*}{ ULW } & CTRL & 238 & 374.8 & 389.1 & 0.82 & 14.3 & 3.8 & 33.9 \\
\hline & INTL & 238 & 374.8 & 379.3 & 0.82 & 7.3 & 1.9 & 31.7 \\
\hline & MODS & 238 & 374.8 & 382.1 & 0.83 & 4.5 & 1.2 & 30.8 \\
\hline & INMO & 238 & 374.8 & 379.1 & 0.86 & 4.3 & 1.1 & 31.3 \\
\hline \multirow{4}{*}{ NR } & CTRL & 238 & 130.1 & 141.9 & 0.86 & 11.8 & 9.1 & 124.1 \\
\hline & INTL & 238 & 130.1 & 143.1 & 0.86 & 13 & 10.0 & 125.9 \\
\hline & MODS & 238 & 130.1 & 143.8 & 0.84 & 13.7 & 10.5 & 132.3 \\
\hline & INMO & 238 & 130.1 & 141.7 & 0.87 & 11.6 & 8.9 & 124.8 \\
\hline \multirow{4}{*}{$\mathrm{SH}$} & CTRL & 238 & 25.8 & 69.4 & 0.74 & 43.6 & 168.9 & 99.1 \\
\hline & INTL & 238 & 25.8 & 60.7 & 0.75 & 34.9 & 135.2 & 87.5 \\
\hline & MODS & 238 & 25.8 & 64.4 & 0.74 & 38.6 & 149.6 & 70.1 \\
\hline & INMO & 238 & 25.8 & 58.2 & 0.77 & 32.4 & 125.5 & 82.9 \\
\hline \multirow{4}{*}{ LH } & CTRL & 238 & 96.9 & 64.4 & 0.83 & -32.5 & -33.5 & 74.8 \\
\hline & INTL & 238 & 96.9 & 69.7 & 0.84 & -27.2 & -28.1 & 69.1 \\
\hline & MODS & 238 & 96.9 & 65.9 & 0.83 & -31 & -32.0 & 74.4 \\
\hline & INMO & 238 & 96.9 & 72.6 & 0.85 & -24.3 & -25.1 & 66.3 \\
\hline \multirow{4}{*}{ SHF } & CTRL & 238 & 6.9 & 0.6 & 0.72 & -6.3 & 91.3 & 46.4 \\
\hline & INTL & 238 & 6.9 & 1.7 & 0.74 & -5.2 & 75.4 & 45.4 \\
\hline & MODS & 238 & 6.9 & 3.4 & 0.76 & -3.5 & 50.7 & 45.0 \\
\hline & INMO & 238 & 6.9 & 4.7 & 0.78 & -2.2 & 31.8 & 44.3 \\
\hline \multirow{4}{*}{ ST } & CTRL & 238 & 14.4 & 17.6 & 0.63 & 3.2 & 22.2 & 5.4 \\
\hline & INTL & 238 & 14.4 & 15.5 & 0.68 & 1.1 & 8.0 & 4.5 \\
\hline & MODS & 238 & 14.4 & 16.5 & 0.65 & 2.1 & 14.6 & 5.1 \\
\hline & INMO & 238 & 14.4 & 15.4 & 0.69 & 1.0 & 9.0 & 4.4 \\
\hline \multirow{4}{*}{ SM } & CTRL & 238 & 0.38 & 0.20 & -0.34 & -0.18 & -47.3 & 0.19 \\
\hline & INTL & 238 & 0.38 & 0.23 & -0.06 & -0.15 & -39.4 & 0.16 \\
\hline & MODS & 238 & 0.38 & 0.22 & -0.30 & -0.16 & -42.1 & 0.17 \\
\hline & INMO & 238 & 0.38 & 0.24 & -0.28 & -0.14 & -36.8 & 0.15 \\
\hline
\end{tabular}

deviation reaches $162 \mathrm{~W} \cdot \mathrm{m}^{-2}$. This effect might be due to the limitation of the Monin-Obukhov similarity theory (MOST) used in the WRF. Recently, variational methods have been used to take into consideration both observations and MOST has been used to improve the sensible heat flux computations $[5,21,22]$. In future research, we will explore this observation more fully.
TABLE 4: Land surface information and parameters at Arou.

\begin{tabular}{lcccc}
\hline Experiment & Land use & $\begin{array}{c}\text { Vegetation } \\
\text { fraction (\%) }\end{array}$ & Albedo & Emissivity \\
\hline CTRL & Open shrublands & 38.16 & 0.213 & 0.936 \\
INTL & Open shrublands & 38.16 & 0.214 & 0.936 \\
MODS & Grasslands & 34.47 & 0.216 & 0.927 \\
INMO & Grasslands & 34.47 & 0.216 & 0.927 \\
\hline
\end{tabular}

The observed albedo is 0.218 .

In Figure 4(c), the model can simulate the diurnal variability of LH (with $R$ of 0.83 to 0.85 ), and the LH is overestimated in four experiments, especially in CTRL experiment; the ME is equal to -32.5 . In Figure $4(\mathrm{~d})$, the modeled SHF are around $20 \mathrm{~W} \cdot \mathrm{m}^{-2}$ larger than the observations during the day and approximately $50 \mathrm{~W} \cdot \mathrm{m}^{-2}$ smaller than the observations at night. Therefore, the simulated SHF is obviously underestimated in experiments $(\mathrm{ME}=-6.3,-5.2,-3.5$, and -2.2 , resp.). This may be due to the modeled soil heat flux (SHF) values modeled at the soil surface, but the observations are measured at $5 \mathrm{~cm}$ depth in the soil. The heat storage effect at a depth of $0-5 \mathrm{~cm}$ reduces the diurnal range of soil heat flux.

3.2.3. Soil Temperature and Humidity. In Figure 5(a), the model can reproduce the variation of soil temperature (ST) $(R$ $=0.63,0.68,0.65$, and 0.69 , resp.) and the ST is overestimated with $\mathrm{MB}$ of 1 to 3.2, for example, during the period from June 16 to June 20. Among the four experiments, the simulations in the INMO experiment are closest to the observations; the CTRL experiment always displays the maximum bias due to the largest soil temperature. Figure 5(b) shows the comparison of soil moisture between observed and simulated results. The experiments significantly underestimate the soil moisture, with $\mathrm{MB}$ of -0.18 to -0.14 and $\mathrm{NMB}$ of -47.3 to -36.8 . The maximum underestimation occurs in CTRL experiment, and the simulation in INTL experiment is closer to the observation compared with the MODS experiment. The simulation period in this study is relatively short, so the initial values of soil temperature and moisture have greater impact on the simulation compared with the new MODISbased land-use data.

3.2.4. Near-Surface Meteorological Fields. A comparison of the modeled and observed near-surface meteorological elements is shown in Figure 6, and the corresponding statistical analysis is presented in Table 5. In Figure 6(a), T2 is well represented ( $R$ of 0.77 to 0.81 ) and overestimated in four experiments. The overestimation of T2 is due to overestimated net energy flux $(\mathrm{NE}, \mathrm{NE}=\mathrm{SW}+\mathrm{LW}+\mathrm{LH})$ at surface. The observed mean NE is $681.8 \mathrm{wm}^{2}$ in June, while the larger NEs $(730.4,716.5,721.4$, and 715.1) are for CTRL, INTL, MODS, and INMO experiments, respectively. Larger surface NE leads to higher T2, and the maximum overestimation of T2 occurs in CTRL experiment $(\mathrm{NMB}=24.4 \%)$ and the minimum in INMO experiment $(\mathrm{NMB}=18.5 \%)$, and the simulation precision in INTL experiment is higher $(\mathrm{RMSE}=21.4)$ than $\mathrm{MODS}$ experiment $(\mathrm{RMSE}=23.2)$. 


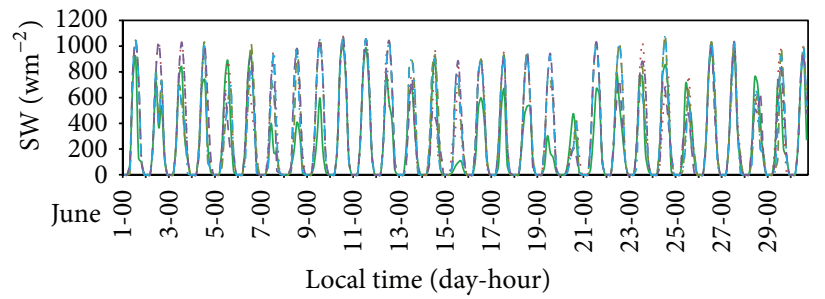

$\begin{array}{ll}\text { - Observation } & --- \text { MODS } \\ \cdots & \text { CTRL }\end{array}$

- - INTL

(a)

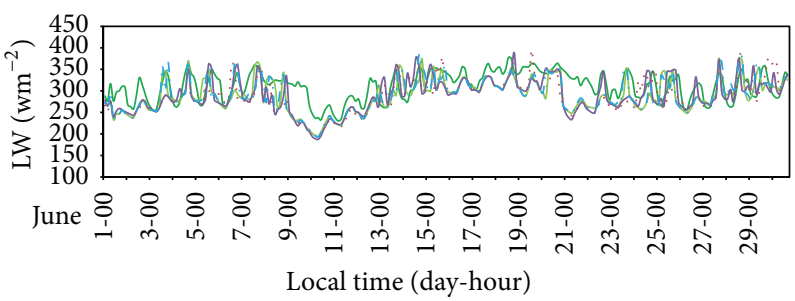

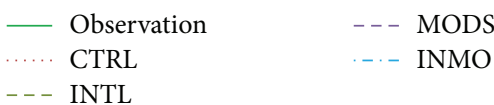

(c)

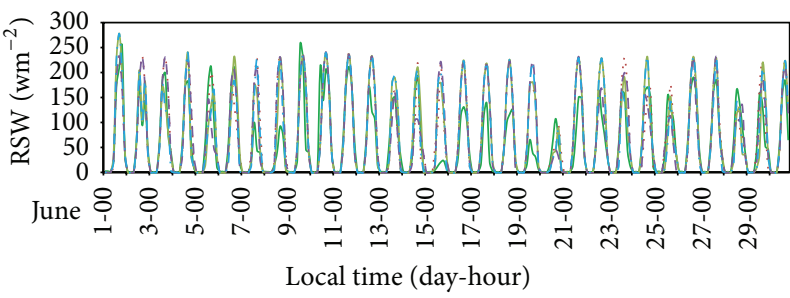

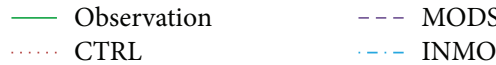

-.- INTL

(b)

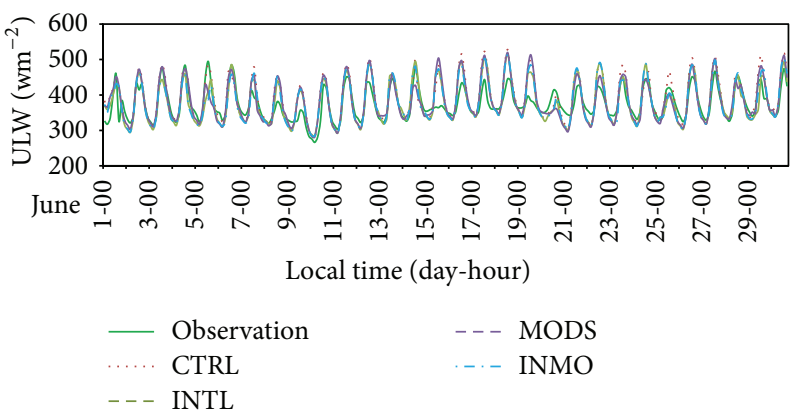

(d)

Figure 3: Comparison of modeled and observed surface radiation at Arou station: (a) solar short-wave radiation (SW), (b) reflected shortwave radiation (RSW), (c) atmospheric long-wave radiation (LW), and (d) upward long-wave radiation (ULW).

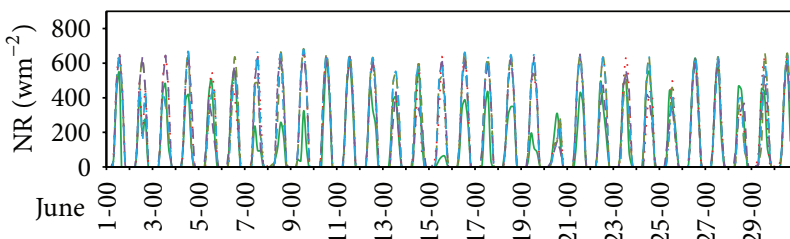

Local time (day-hour)

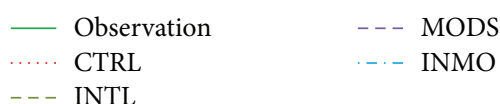

(a)

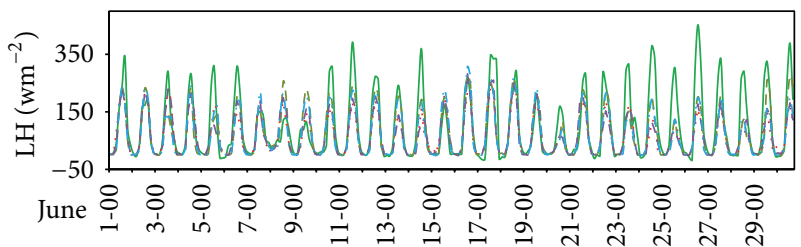

Local time (day-hour)

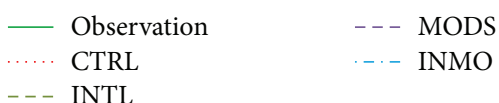

(c)

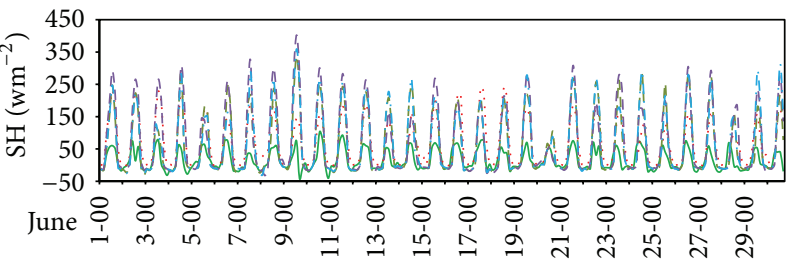

Local time (day-hour)

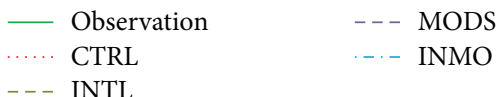

(b)

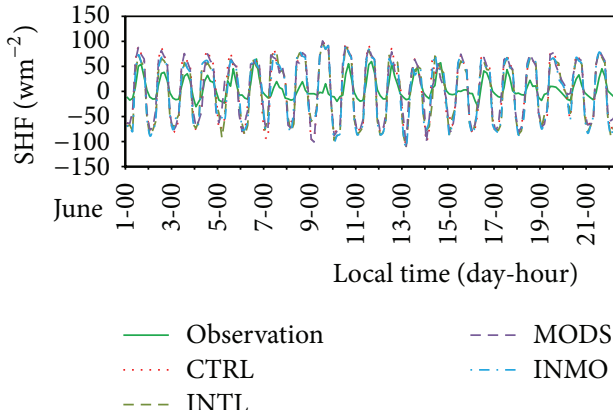

(d)

FIGURE 4: Comparison of modeled and observed surface flux at Arou station: (a) net radiance (NR), (b) sensible heat flux (SH), (c) latent heat flux (SH), and (d) soil heat flux (SHF). 


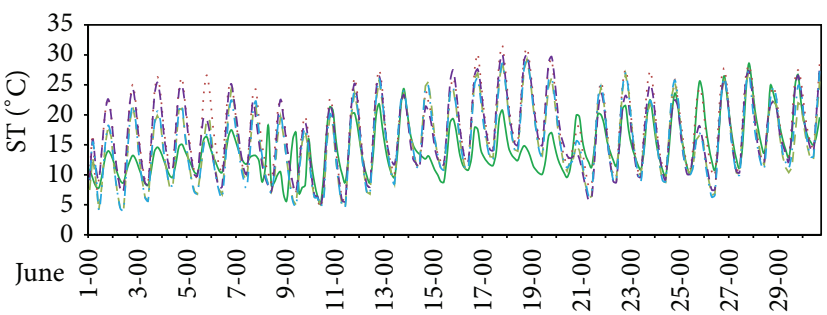

Local time (day-hour:min)

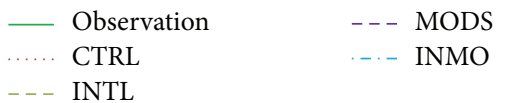

(a)

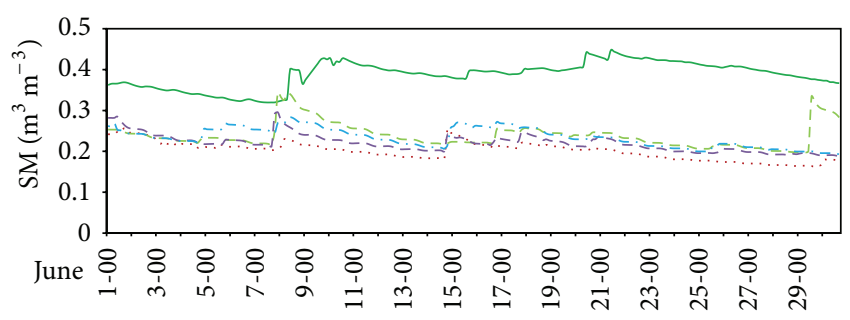

Local time (day-hour:min)

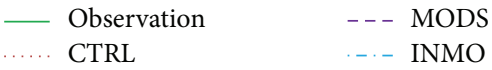

(b)

Figure 5: Comparison of modeled and observed $10 \mathrm{~cm}$ soil temperature and moisture at Arou station: (a) soil temperature (ST) and (b) soil moisture (SM).

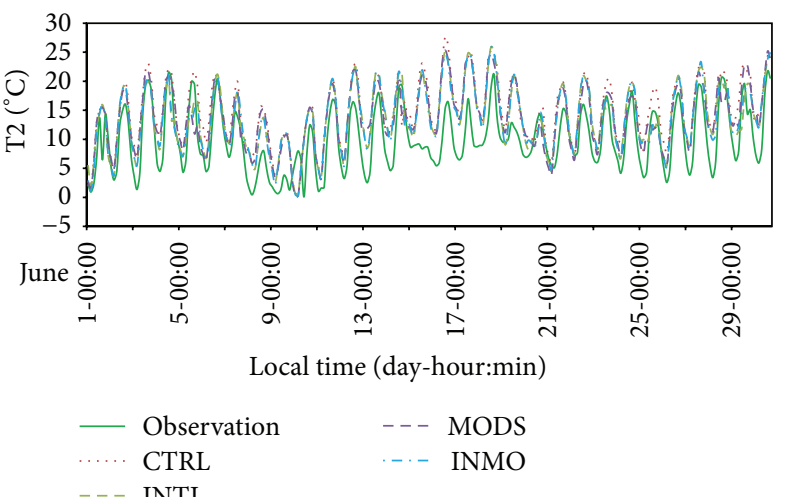

(a)

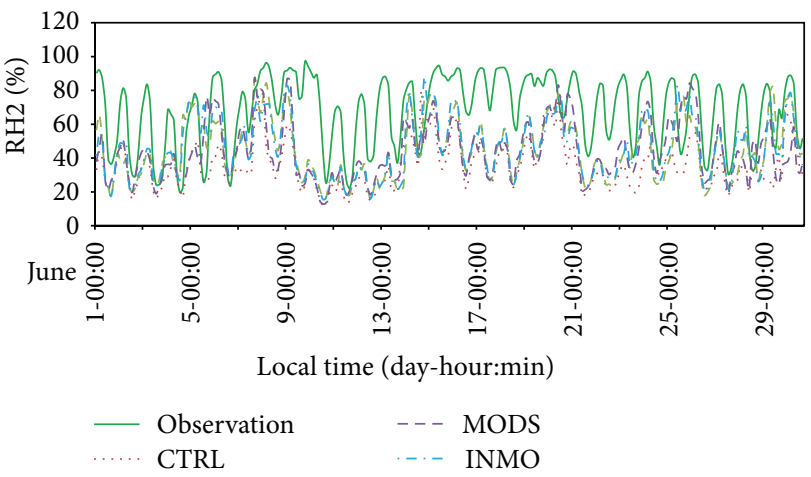

(b)

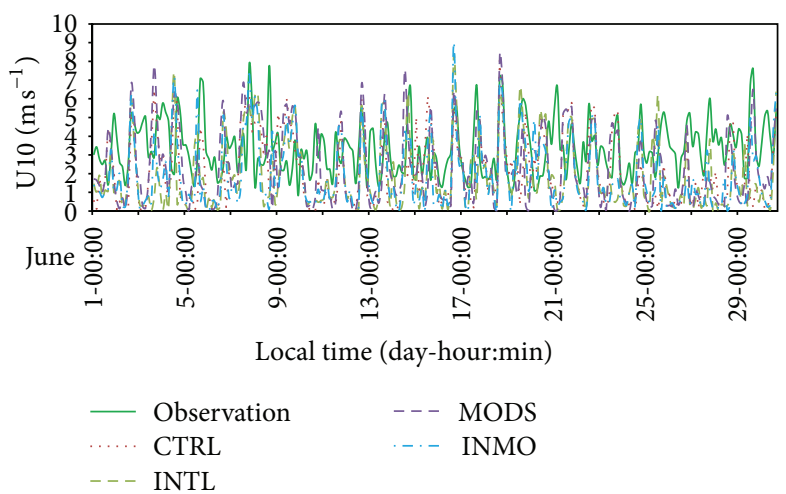

(c)

FiguRE 6: Modeled and observed near-surface meteorological field at Arou station: (a) $2 \mathrm{~m}$ temperature (T2), (b) 2 m relative humidity (RH2), and (c) $10 \mathrm{~m}$ wind speed (U10).

In Figure 6(b), the four experiments approximately simulate the daily variation in the $2 \mathrm{~m}$ relative humidity, with $R$ of 0.50 to 0.55 . Specifically, $\mathrm{RH} 2$ is obviously underestimated in CTRL experiment $(\mathrm{MB}=-30.6)$, due to the overestimated temperature at surface under insignificant change of water vapor pressure. Compared with CTRL experiment, the simulation is improved in three sensitivity experiments, because of the lower values of modeled T2. Additionally, the higher soil moisture in sensitivity experiment increases the soil heat capacity and thermal conductivity and then augments the surface evaporation. The highest improvement in $\mathrm{RH} 2$ is in INMO experiment, followed by INTL experiment and then MODS experiment.

In Figure 6(c), for the $10 \mathrm{~m}$ wind speed, the simulated values are lower than the observations, and the simulation precision is very low in these four experiments (with $R$ of 0.16 to 0.21 ). Previous studies have demonstrated that systematic biases exist in WRF modeling of wind speed in complex terrain areas [10]. Therefore we designed another JIME experiment that uses the Jimenez scheme as 


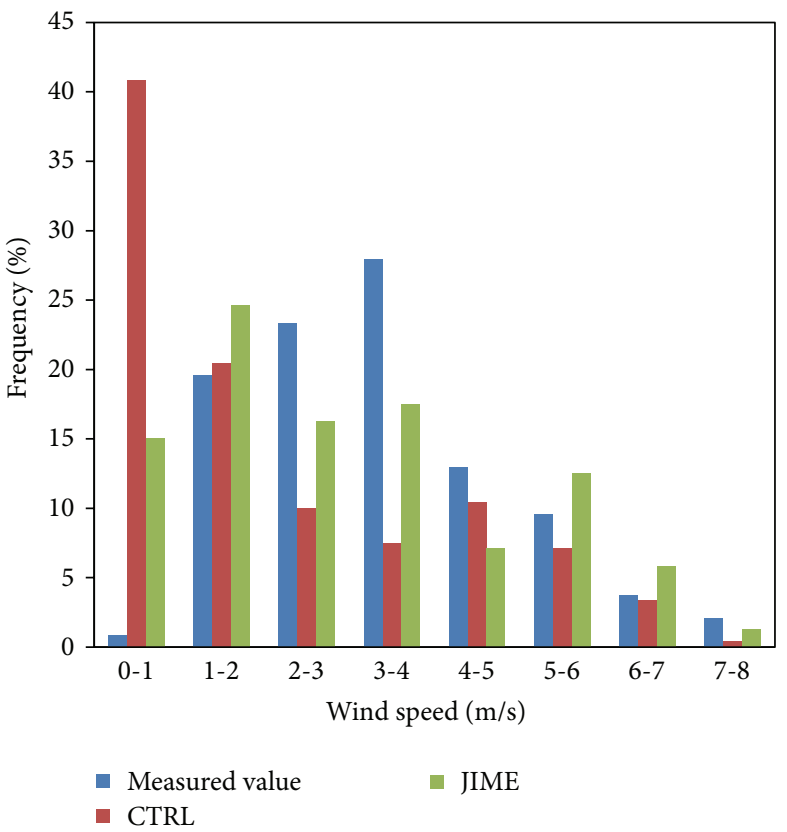

(a)

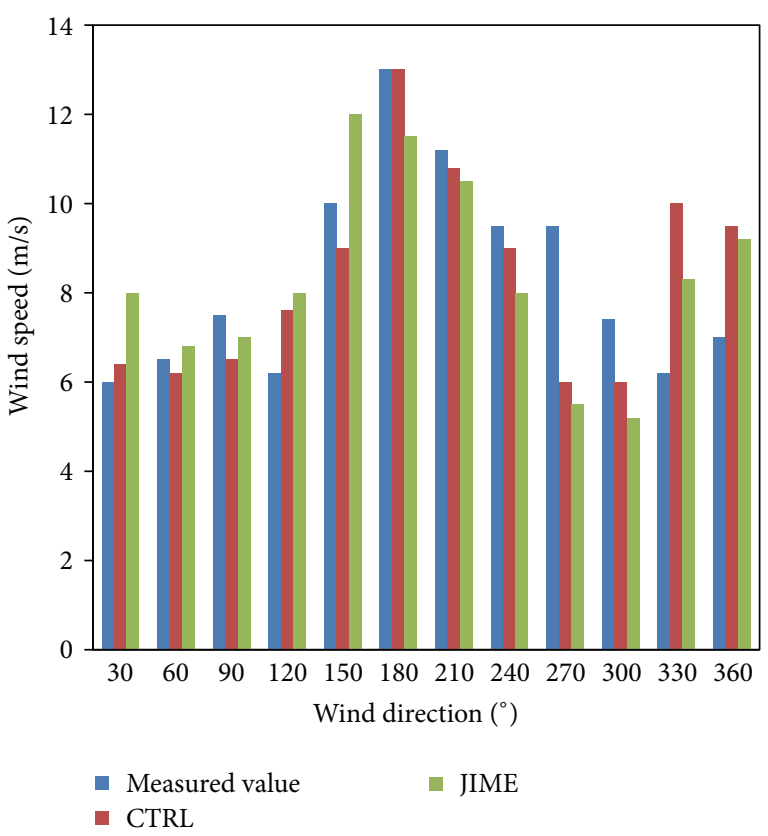

(b)

FIGURE 7: Figures of probability density distribution: (a) wind speed and (b) wind direction.

TABLE 5: Statistics of $2 \mathrm{~m}$ temperature T2, RH2, and $U 10$ between the observation and model results at Arou station.

\begin{tabular}{ccccccccc}
\hline & & $N$ & $C_{\mathrm{OBS}}$ & $C_{\mathrm{MOD}}$ & $R$ & $\mathrm{MB}$ & $\mathrm{NMB}(\%)$ & $\mathrm{RMSE}$ \\
\hline \multirow{4}{*}{ T2 } & CTRL & 238 & 11.2 & 14.8 & 0.77 & 3.6 & 24.4 & 32.1 \\
& INTL & 238 & 11.2 & 13.6 & 0.80 & 2.4 & 19.8 & 21.4 \\
& MODS & 238 & 11.2 & 13.8 & 0.79 & 2.6 & 20.4 & 23.2 \\
& INMO & 238 & 11.2 & 13.5 & 0.81 & 2.3 & 18.5 & 20.5 \\
\hline \multirow{6}{*}{$\mathrm{RH} 2$} & CTRL & 238 & 68.1 & 37.5 & 0.50 & -30.6 & -44.9 & 36.7 \\
& INTL & 238 & 68.1 & 42.9 & 0.51 & -25.2 & -37.0 & 30.0 \\
& MODS & 238 & 68.1 & 44.0 & 0.53 & -24.1 & -35.3 & 29.8 \\
& INMO & 238 & 68.1 & 46.8 & 0.55 & -21.3 & -31.2 & 29.1 \\
\hline \multirow{6}{*}{ U10 } & CTRL & 238 & 3.3 & 2.1 & 0.18 & -1.2 & -36.4 & 2.5 \\
& INTL & 238 & 3.3 & 1.9 & 0.16 & -1.4 & -42.4 & 2.6 \\
& MODS & 238 & 3.3 & 2.4 & 0.20 & -0.9 & -27.3 & 2.4 \\
& INMO & 238 & 3.3 & 2.0 & 0.21 & -1.3 & -39.4 & 2.5 \\
\hline
\end{tabular}

the subgrid-scale orography parameterization scheme. As the results in Figure 7(a) show, the CTRL experiment significantly overestimates the frequency of wind speeds below $1 \mathrm{~m} / \mathrm{s}$ and underestimates significantly the frequency of wind speed between 2 and $4 \mathrm{~m} / \mathrm{s}$. Compared with the CTRL experiment, the JIME experiment greatly decreases the frequency of low wind speed and increases the frequency of high wind speeds, which is more consistent with the frequency of the observations of wind speed. As shown in Figure 7(b), the wind direction changes frequently and is directed mainly toward the south during the research period. The simulated wind direction is similar in the two experiments. Figure 8 shows the mean hourly wind speed at Arou station in June. The two experiments accurately simulate the daily variation in wind speed. However, the simulated wind speeds are

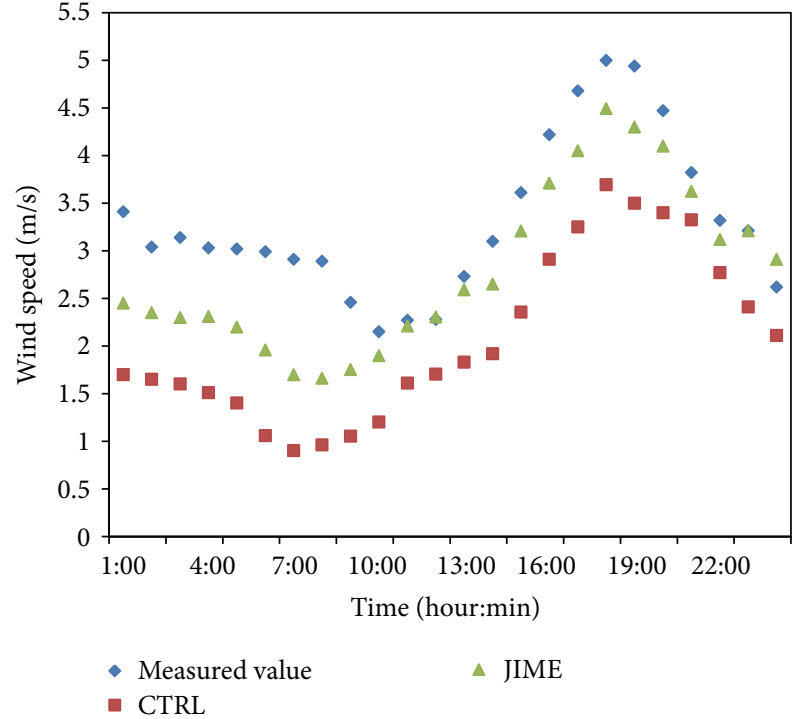

FIGURE 8: Mean hourly wind speed at Arou station in June.

lower than the observations for almost all hours and exhibit a larger difference between the CTRL experiment and the observations.

\section{Impacts of Driving and Land-Use Data on the Structure of the Atmospheric Boundary Layer}

4.1. Thickness of the Atmospheric Boundary Layer. The changes in the driving and land-use data cause the redistribution of surface energy and thus influence the development of the 


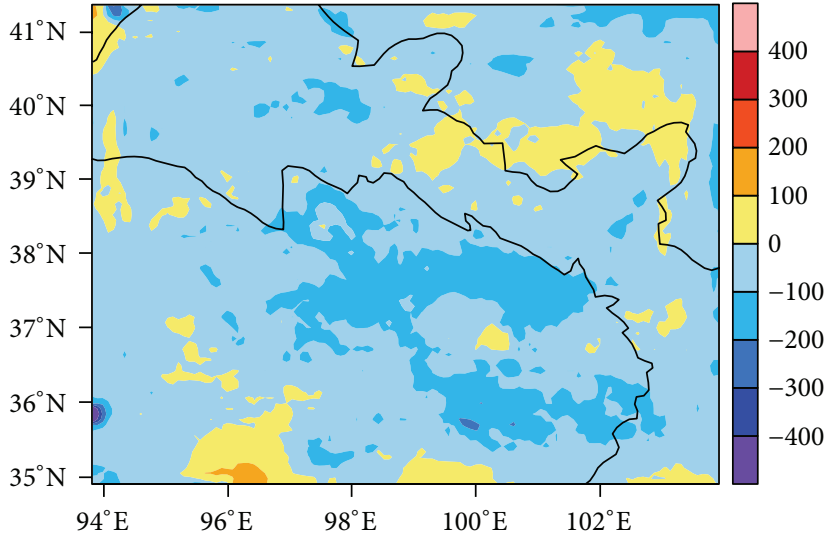

(a)

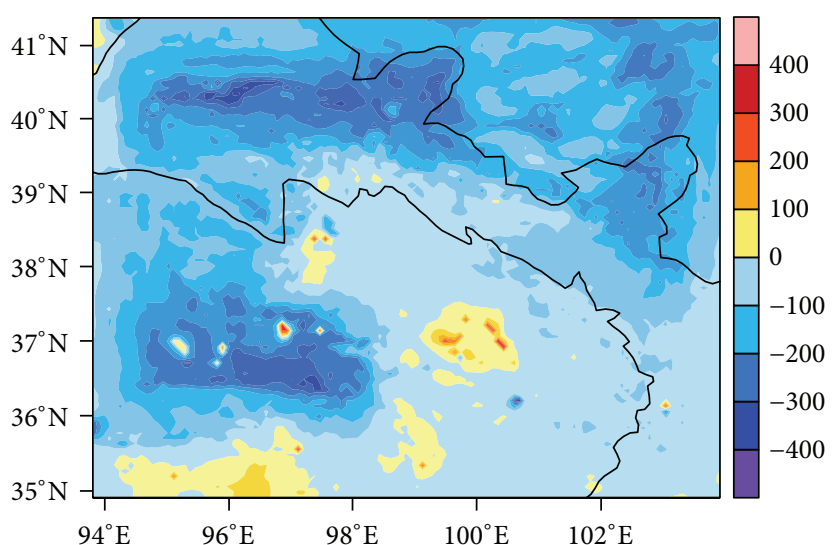

(c)

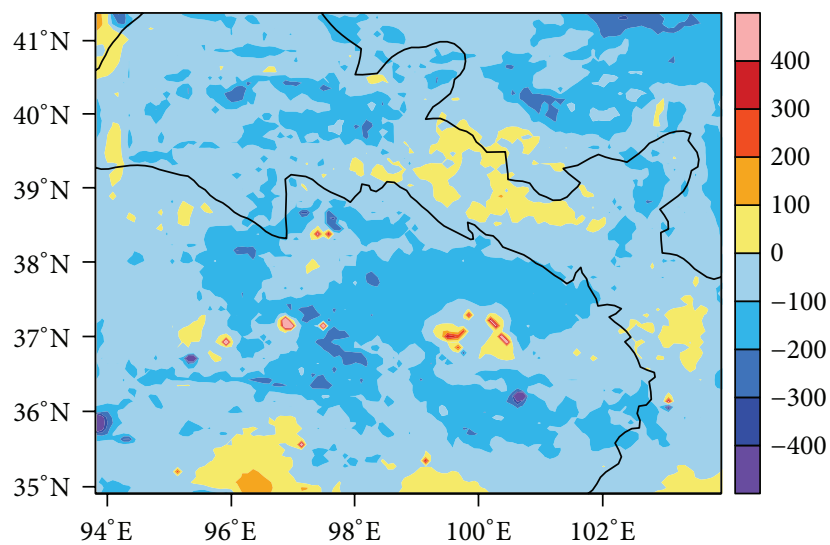

(e)

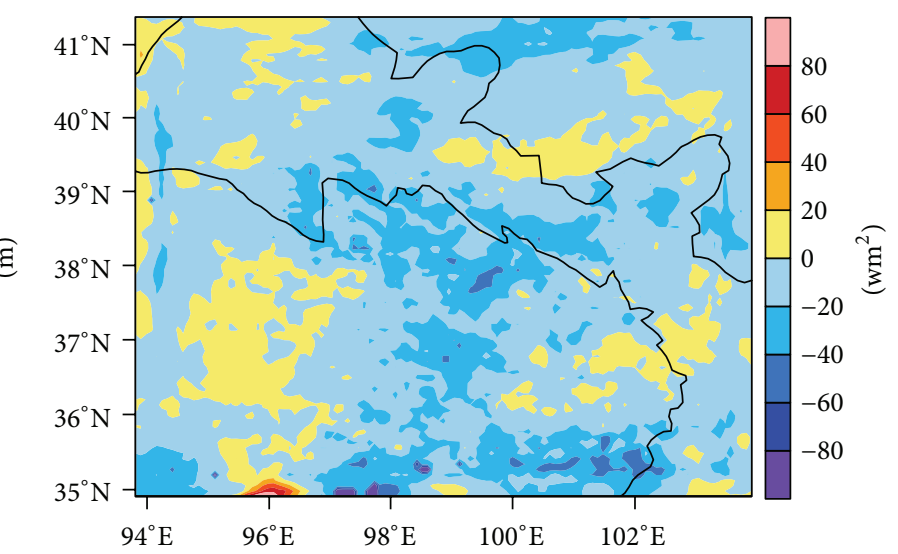

(b)

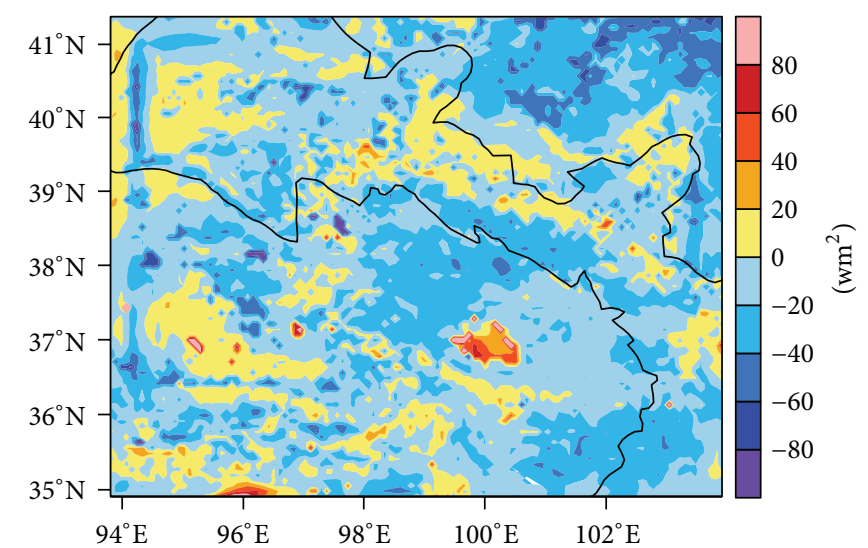

(d)

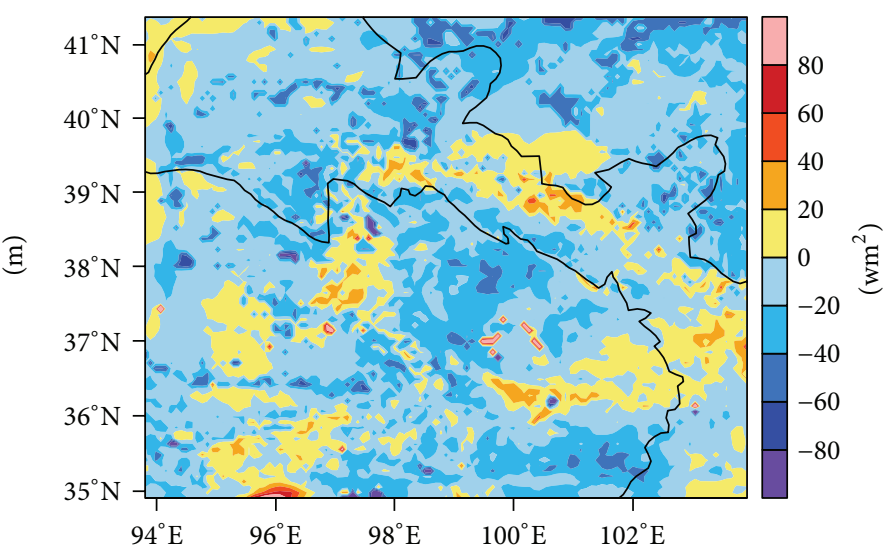

(f)

FIGURE 9: Spatial difference for mean boundary layer height (BLH) and mean net energy flux in June (NE): (a) INTL-CTRL for BLH; (b) INTL-CTRL for NE; (c) MODS-CTRL for BLH; (d) MODS-CTRL for NE; (e) INMO-CTRL for BLH; (f) INMO-CTRL for NE.

boundary layer. Figure 9 shows the spatial difference of the mean boundary layer height (BLH) in June. Compared with the CTRL experiment $(\mathrm{BLH}=758.5 \mathrm{~m})$, the boundary layer heights averaged for the study area are larger in the INTL (712.1 m), MODS (703 m), and INMO (684.5 m) experiments (Figures 9(a), 9(c), and 9(e)), due to the smaller surface net energy flux (Figures 9(b), 9(d), and 9(f)). The surface $\mathrm{NE}$ averaged in the study area is $731.2 \mathrm{wm}^{2}$ in CTRL, and the NEs are $717.9 \mathrm{wm}^{2}, 715.3 \mathrm{wm}^{2}$, and $710.7 \mathrm{wm}^{2}$ in INTL,
MODS, and INMO experiments, respectively. Additionally, the variation in boundary layer height is related to turbulent transport, which is affected by the temperature and humidity conditions near the ground. A warmer and drier near-surface layer is conducive to the development of the boundary layer. As shown in Table 2, the mean T2 is highest and the mean RH2 humidity is lowest in CTRL experiment, and the higher T2 and lower RH2 lead to larger BLH in CTRL experiment. 


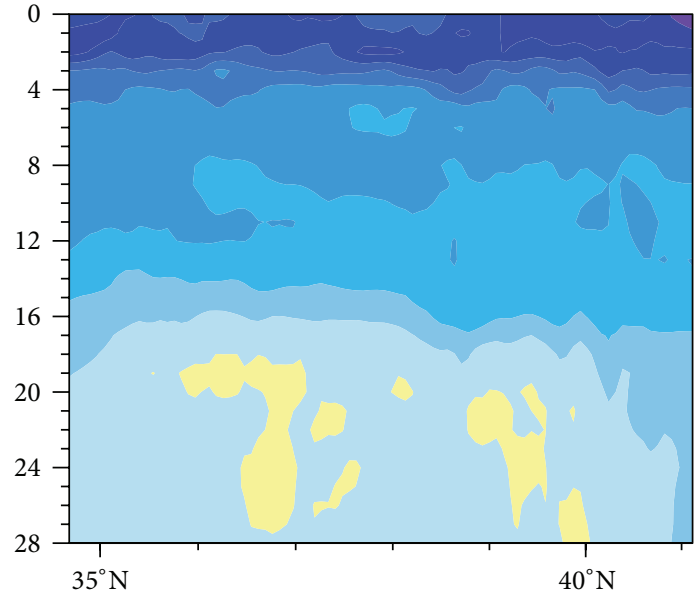

(a)

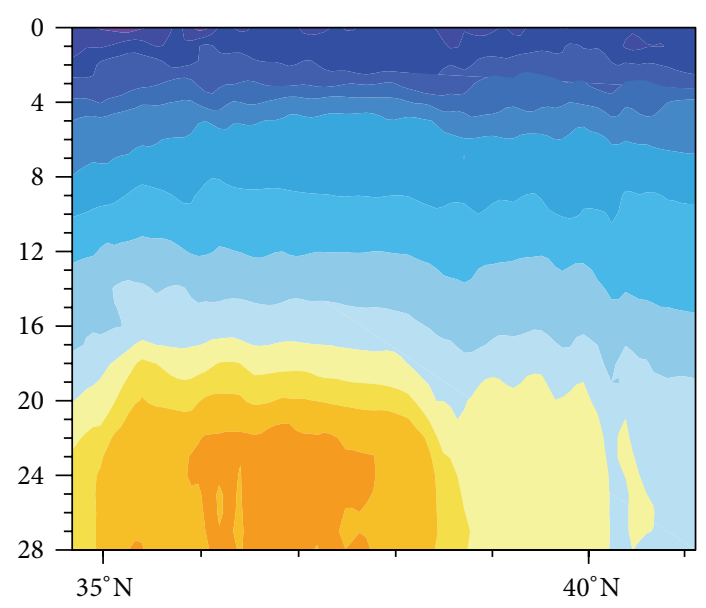

(c)

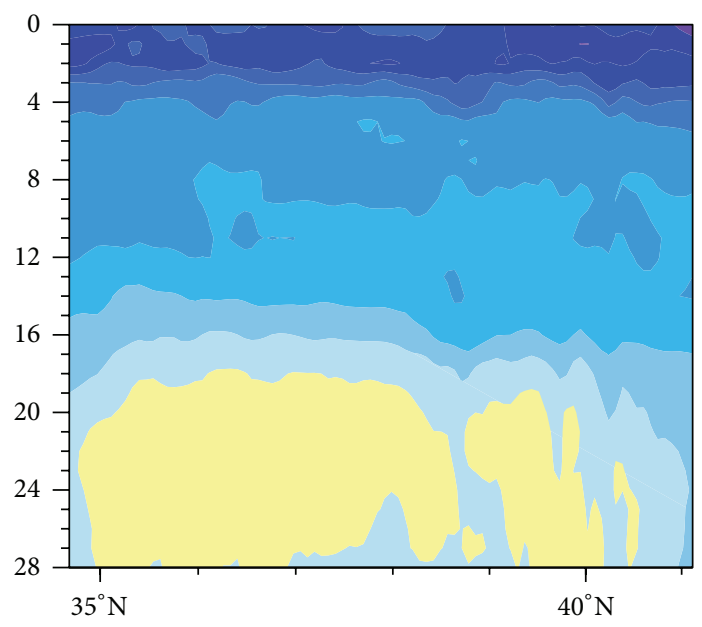

(e)
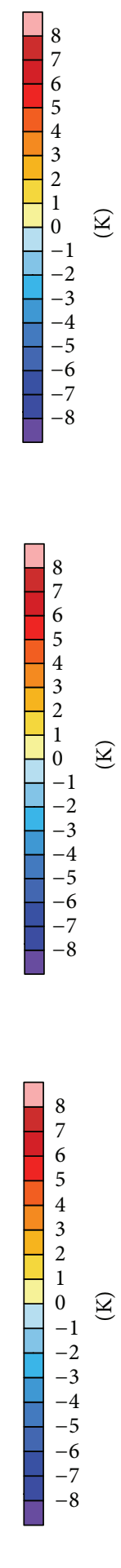

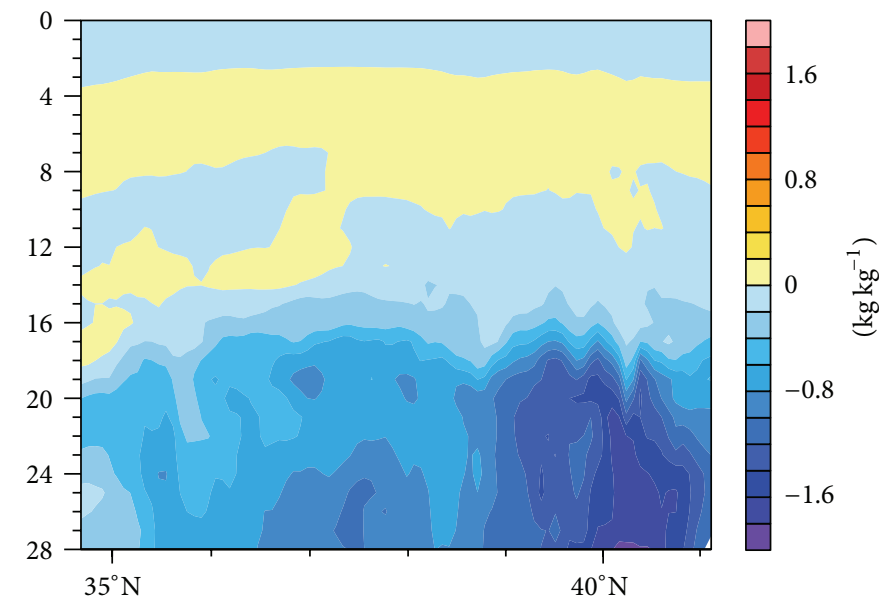

(b)

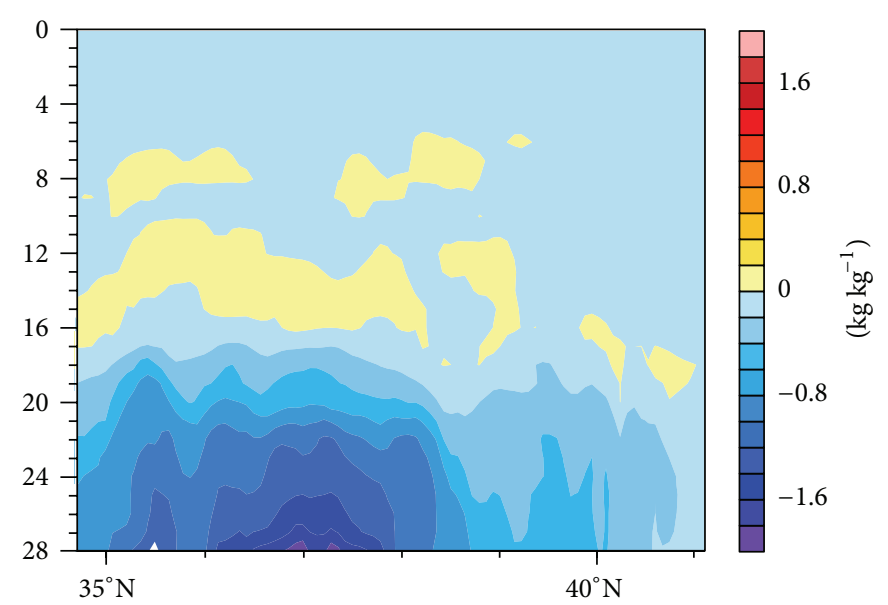

(d)

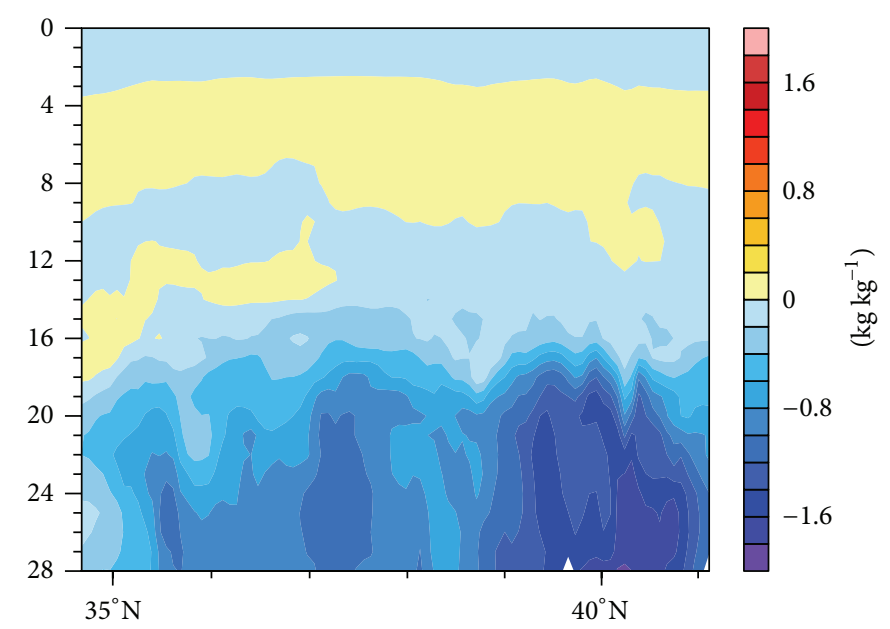

(f)

FIGURE 10: Vertical profile difference for the average potential temperature and water vapor mixing ratio along $100.46^{\circ} \mathrm{E}$ in June: (a) INTLCTRL for potential temperature, (b) INTL-CTRL for water vapor mixing ratio, (c) MODS-CTRL for potential temperature, (d) MODS-CTRL for water vapor mixing ratio, (e) INMO-CTRL for potential temperature, and (f) INMO-CTRL for water vapor mixing ratio. 


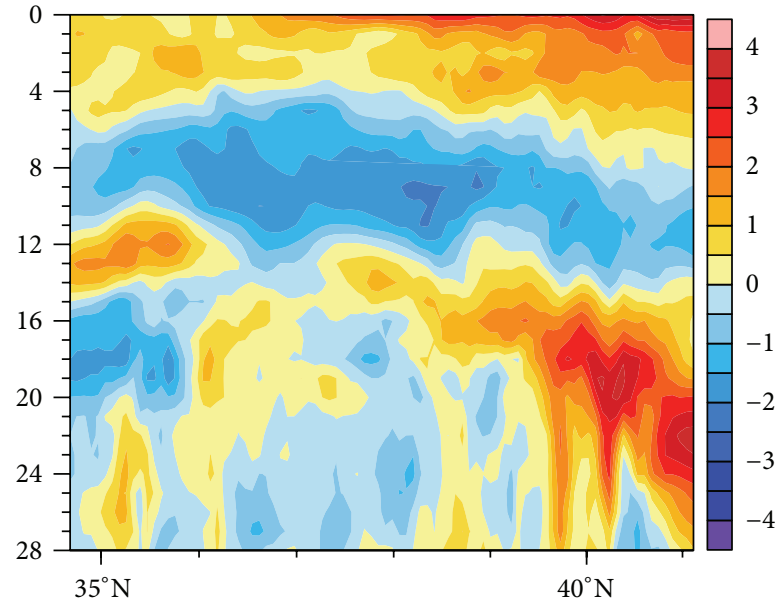

(a)

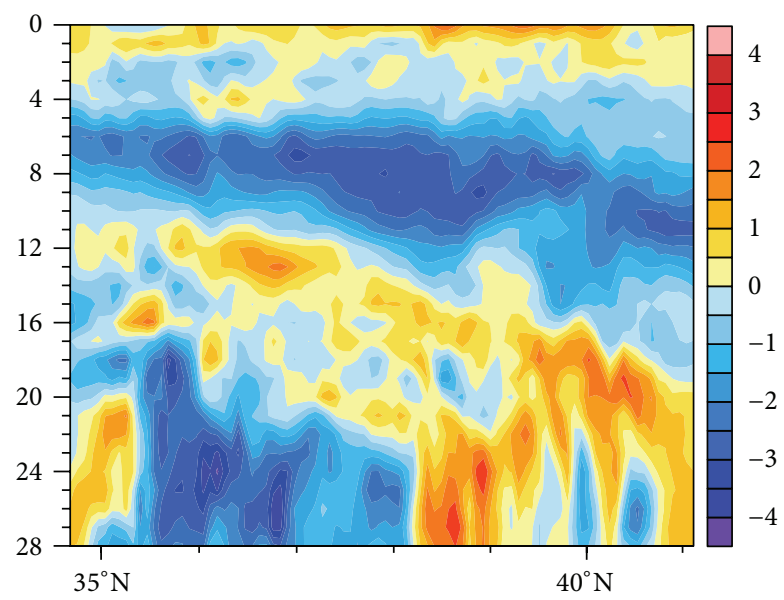

(c)

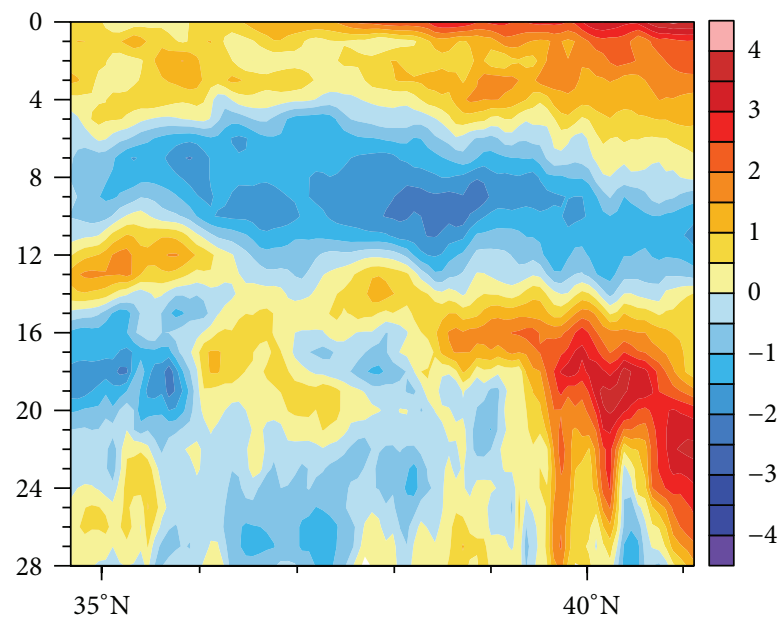

(e)

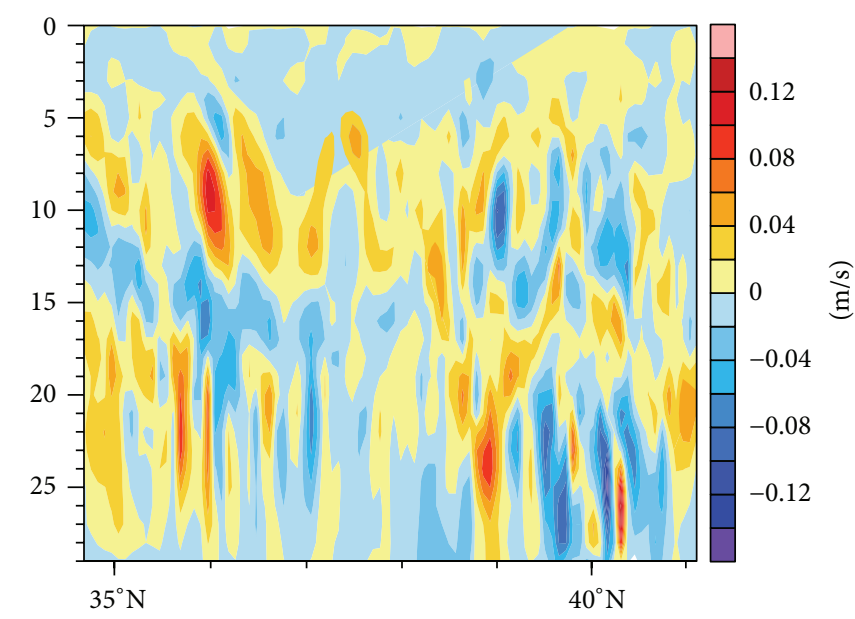

(b)

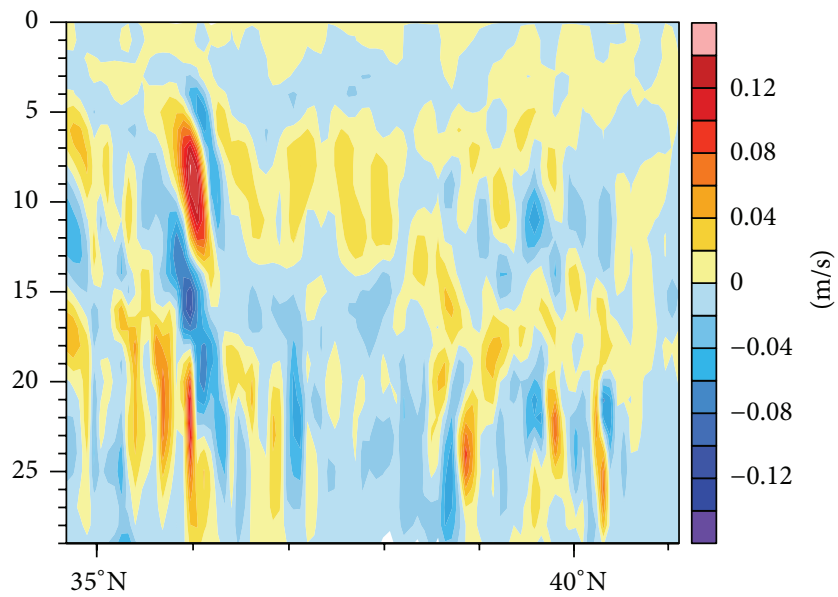

(d)

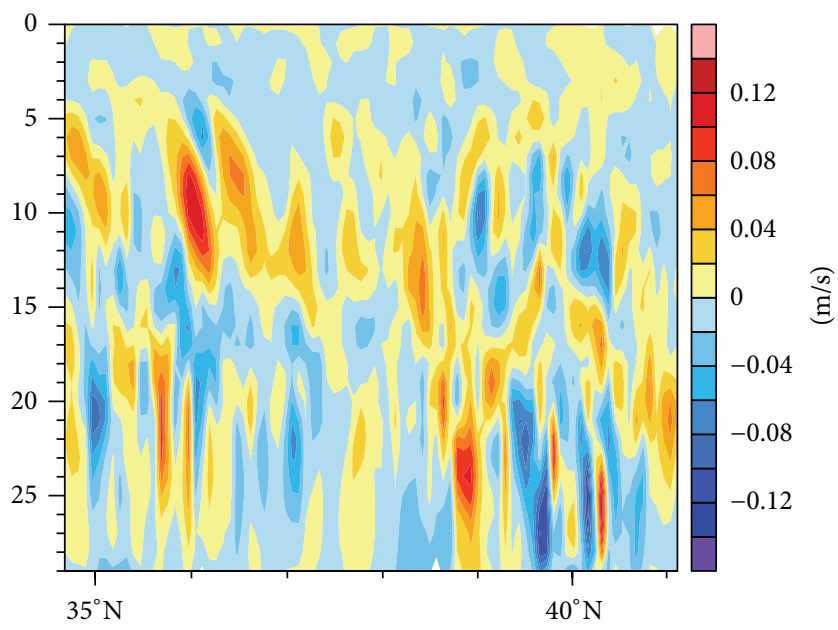

(f)

FIGURE 11: Vertical profile difference for average $U$ and $\mathrm{W}$ wind speed along $100.46^{\circ} \mathrm{E}$ in June: (a) INTL-CTRL for U wind speed, (b) INTLCTRL for W wind speed, (c) MODS-CTRL for U wind speed, (d) MODS-CTRL for W wind speed, (e) INMO-CTRL for U wind speed, and (f) INMO-CTRL for $\mathrm{W}$ wind speed. 


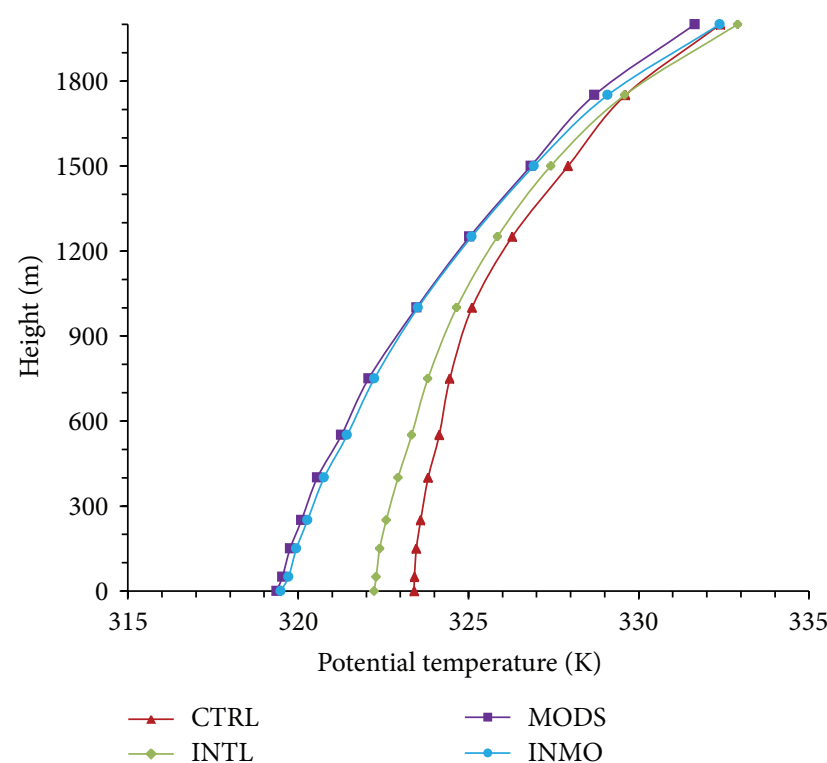

(a)

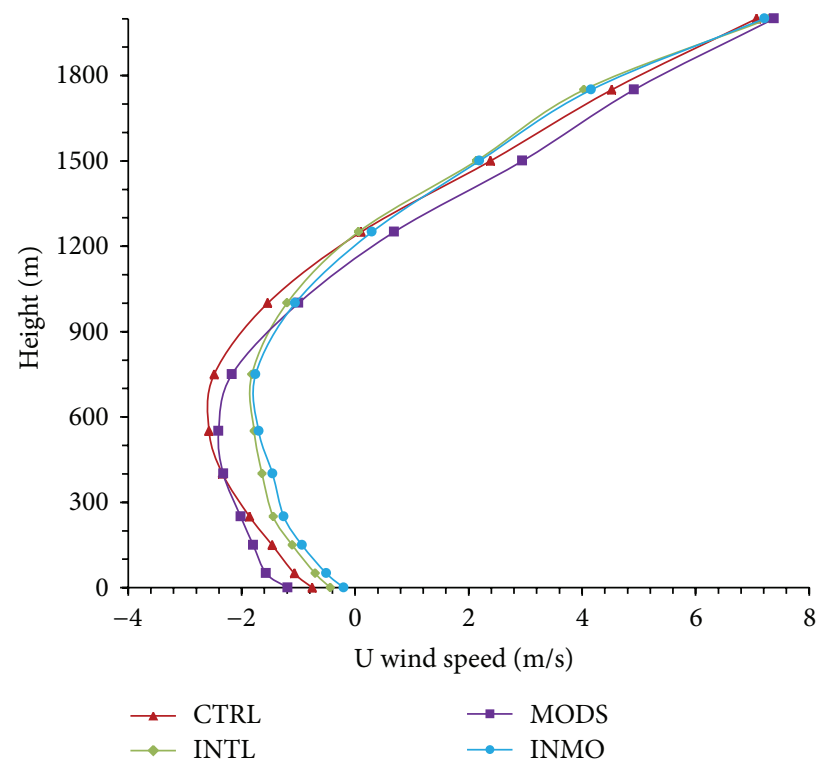

(c)

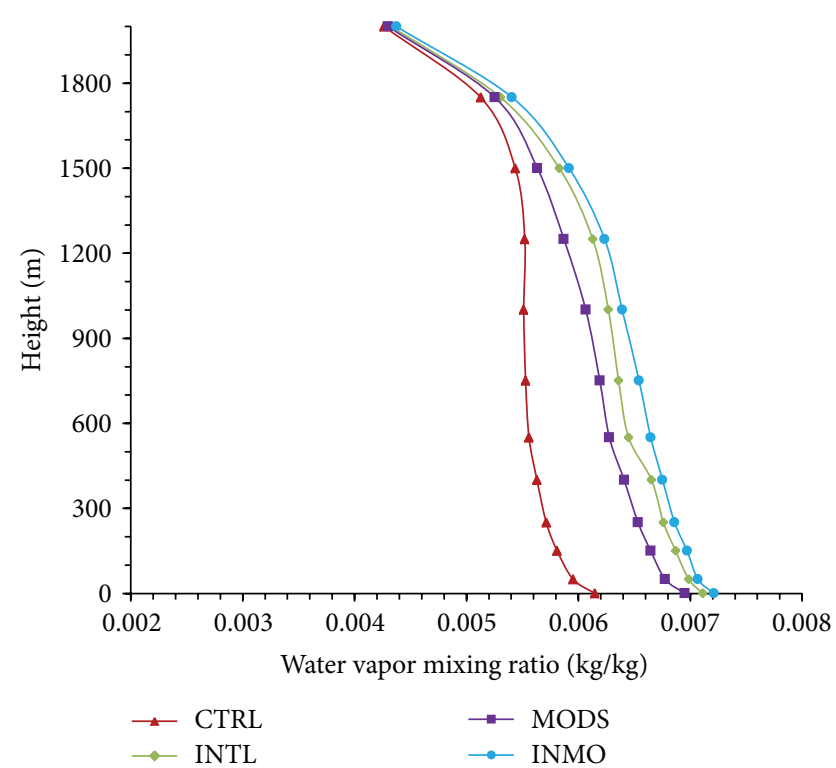

(b)

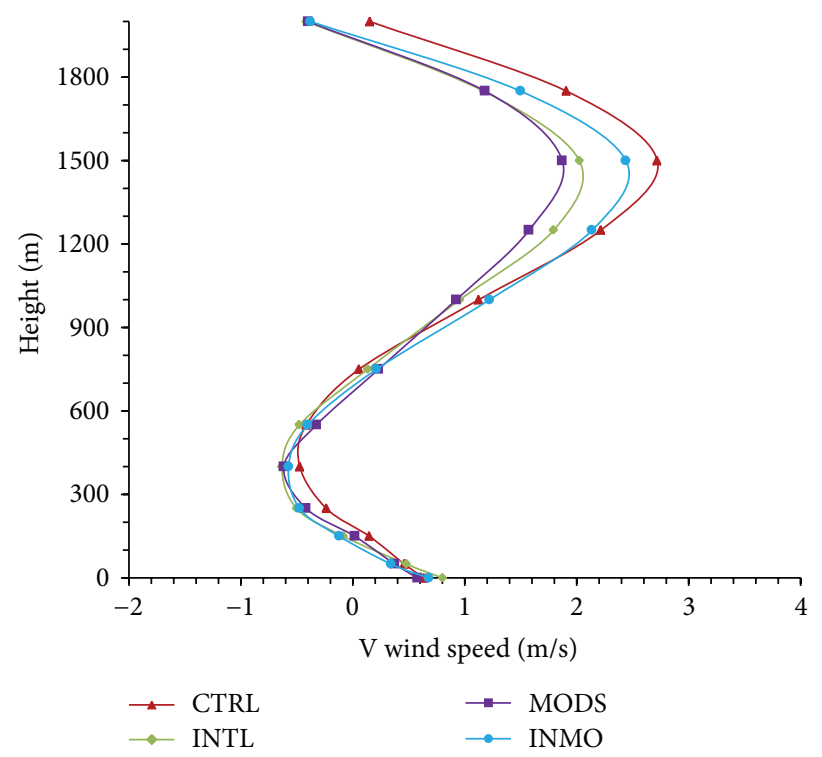

(d)

FIGURE 12: Average vertical profile of the boundary layer at Arou station in June at 12:00: (a) potential temperature, (b) water vapor mixing ratio, (c) U wind speed, and (d) V wind speed.

4.2. Structure of the Atmospheric Boundary Layer. Figure 10 shows the vertical profile difference for the average potential temperature and water vapor mixing ratio along $100.46^{\circ} \mathrm{E}$. It can be observed that the impact of the new driving and land-use data is more complicated for potential temperature (Figures 10(a), 10(c), and 10(e)). The changes in potential temperature in the upper atmosphere are not consistent with the changes in the lower atmosphere. The impact on the water vapor mixing ratio is primarily found in the middle and lower atmosphere (Figures 10(b), 10(d), and 10(f)). Figure 11 shows the differences of vertical profile for the average $U$ and $\mathrm{W}$ wind speed along $100.46^{\circ} \mathrm{E}$. The disturbance for $\mathrm{U}$ wind speed is relatively larger than that of $\mathrm{W}$ wind speed. There is a clear extreme value area which can be observed in the lower atmosphere at approximately $40^{\circ} \mathrm{N}$.

Figures 12 and 13 present the average vertical profiles of the boundary layer at Arou station in June at 12:00 and 0:00, respectively. In Figure 12(a), for potential temperature (at 12:00), the boundary layer is warmest in the CTRL experiment, whereas the boundary layer is coldest in the MODS experiment. This observation suggests that the new land-use data have a greater impact on potential temperature compared with the ERA-Interim driving data. At 0:00, compared with the CTRL experiment, the simulated values in the MODS and INMO experiments are higher below $750 \mathrm{~m}$. Generally, the differences for potential temperature 


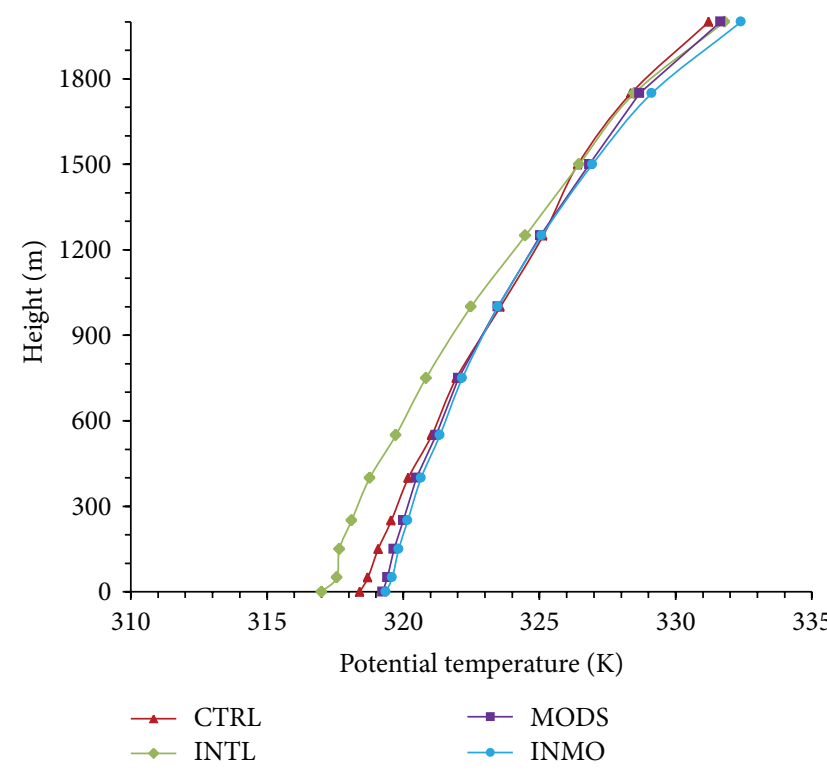

(a)

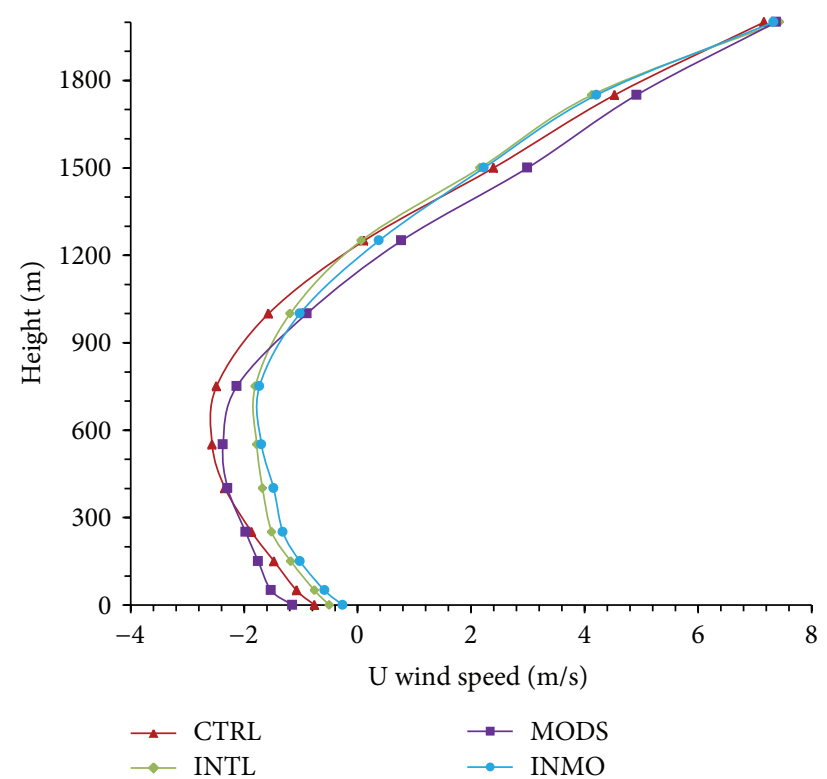

(c)

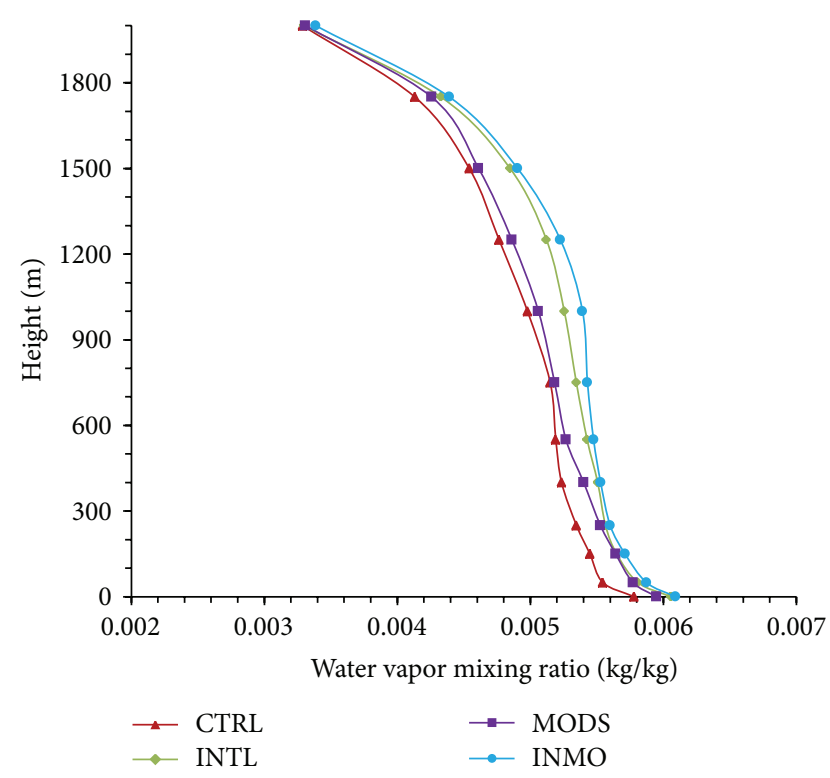

(b)

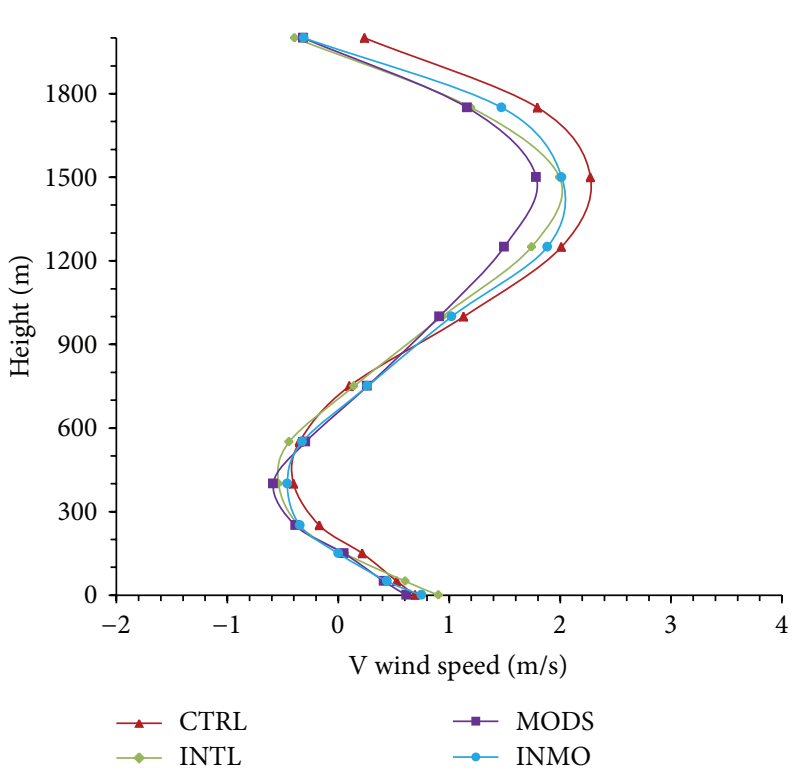

(d)

FIGURE 13: Average vertical profile of boundary layer at Arou station in June at 0:00: (a) potential temperature, (b) water vapor mixing ratio, (c) U wind speed, and (d) V wind speed.

among the four experiments are smaller at 0:00 than that at 12:00.

For the water vapor mixing ratio at 12:00 (Figure 12(b)), the boundary layer in the other three experiments is wetter than in the CTRL experiment, and it is wettest in the INMO experiment. It is clear that the INTL experiment has a larger water vapor mixing ratio compared with the MODS experiment. Additionally, the differences in simulated values are greater in the lower atmosphere than that in the upper atmosphere. At 0:00, for the water vapor ratio (Figure 13(b)), the difference is less than that at 12:00. In Figure 13(c), for $U$ wind speed at 12:00, the difference among the four experiments is larger below $500 \mathrm{~m}$, decreases to
$1000 \mathrm{~m}$, and subsequently begins to increase until $1800 \mathrm{~m}$. As shown in Figure 13(d), the difference in V wind speed at 0:00 is significantly smaller than in $\mathrm{U}$ wind speed. It is also noteworthy that, at 0:00 (Figures 13(c) and 13(d)), the simulated differences for $\mathrm{U}$ and $\mathrm{V}$ wind speeds are similar to those at 12:00.

\section{Summary and Conclusions}

In this paper, we use two types of reanalysis data (NCEP and ERA-Interim) and two sets of MODIS land-use information to evaluate the impact of driving and land-use data on WRF modeling in the northeastern Tibetan Plateau. 
The four experiments are able to accurately simulate the diurnal variation of the $2 \mathrm{~m}$ temperature and relative humidity. The ERA-Interim driving data and updated MODS-based land-use information improve the simulation in T2 and RH2, through the correction of overestimated surface net energy flux and underestimated soil moisture. Previous studies also pointed out that the WRF model is highly sensitive to soil moisture $[23,24]$ and the ERA-Interim reanalysis data have a greater reliability of application in China compared with the NCEP data [25-27]. However, both the new initial driving and underlying surface data do not lead to sufficient improvement for the $10 \mathrm{~m}$ wind speed due to the complex terrain of the Tibetan Plateau. Therefore, we designed another JIME experiment to analyze the effect of topography on the $10 \mathrm{~m}$ wind speed. The JIME experiment greatly decreases the frequency of the low wind speed and increases the frequency of the large wind speed, which is more consistent with the observations. With the ERA-Interim reanalysis and 2010 MODIS-based land-use data, averaged for the study area, the experiments result in a lower boundary layer height due to smaller net energy flux. Additionally, the lower T2 and higher $\mathrm{RH} 2$ in these experiments also make the BLH higher. For the potential temperature and wind speed, the new initial conditions and underlying surface influence the lower atmosphere as well as the upper layer, and the impact on the water vapor mixing ratio is primarily concentrated in the lower atmosphere. Generally, the difference among simulated results in different experiments at 0:00 is less than that at 12:00.

\section{Conflict of Interests}

The authors declare that there is no conflict of interests regarding the publication of this paper.

\section{Acknowledgments}

The National Natural Science Foundation of China (41571062, 41190080, and 41401226) and the China Postdoctoral Science Foundation (Grant no. 2015M570865) jointly support this work. Additionally, the authors would like to acknowledge the Supercomputing Center, Big Data Center of Cold and Arid Regions Environmental and Engineering Research Institute, Chinese Academy of Sciences, for resources and time, and they are grateful to Guohui Zhao for his help of installing some software.

\section{References}

[1] J. R. Minder, P. W. Mote, and J. D. Lundquist, "Surface temperature lapse rates over complex terrain: lessons from the Cascade Mountains," Journal of Geophysical Research: Atmospheres, vol. 115, no. 14, Article ID D14122, pp. 1307-1314, 2010.

[2] R. E. Dickinson, "Land-atmosphere interaction," Reviews of Geophysics, vol. 33, no. 2, pp. 917-922, 1995.

[3] Q. Zhang, J. Zhang, J. Qiao, and S. Wang, "Relationship of atmospheric boundary layer depth with thermodynamic processes at the land surface in arid regions of China," Science China Earth Sciences, vol. 54, no. 10, pp. 1586-1594, 2011.
[4] C. D. Whiteman, Mountain Meteorology: Fundamentals and Applications, Oxford University Press, New York, NY, USA, 2000.

[5] K. W. Appel, R. C. Gilliam, N. Davis, A. Zubrow, and S. C. Howard, "Overview of the atmospheric model evaluation tool (AMET) v1.1 for evaluating meteorological and air quality models," Environmental Modelling and Software, vol. 26, no. 4, pp. 434-443, 2011.

[6] K. W. Appel, S. J. Roselle, R. C. Gilliam, and J. E. Pleim, "Sensitivity of the Community Multiscale Air Quality (CMAQ) model v4.7 results for the eastern United States to MM5 and WRF meteorological drivers," Geoscientific Model Development, vol. 3, no. 1, pp. 169-188, 2010.

[7] K. M. Hines and D. H. Bromwich, "Development and testing of polar weather research and forecasting (WRF) model. Part I. Greenland ice sheet meteorology," Monthly Weather Review, vol. 136, no. 6, pp. 1971-1989, 2008.

[8] C.-Y. Lin, F. Chen, J. C. Huang et al., "Urban heat island effect and its impact on boundary layer development and land-sea circulation over northern Taiwan," Atmospheric Environment, vol. 42, no. 22, pp. 5635-5649, 2008.

[9] S. Hong, V. Lakshmi, E. E. Small, F. Chen, M. Tewari, and K. W. Manning, "Effects of vegetation and soil moisture on the simulated land surface processes from the coupled WRF/Noah model," Journal of Geophysical Research: Atmospheres, vol. 114, no. 18, pp. 3151-3157, 2009.

[10] J.-F. Miao, D. Chen, and K. Borne, "Evaluation and comparison of Noah and Pleim-Xiu land surface models in MM5 using GÖTE2001 data: spatial and temporal variations in nearsurface air temperature," Journal of Applied Meteorology and Climatology, vol. 46, no. 10, pp. 1587-1605, 2007.

[11] Y. Y. Chen, K. Yang, D. G. Zhou, J. Qin, and X. F. Guo, "Improving the noah land surface model in arid regions with an appropriate parameterization of the thermal roughness length," Journal of Hydrometeorology, vol. 11, no. 4, pp. 995-1006, 2010.

[12] Z. Cao and J. Ma, "An application of the variational method to computation of sensible heat flux over a deciduous forest," Journal of Applied Meteorology, vol. 44, no. 1, pp. 144-152, 2005.

[13] J.-H. Jeong, S.-K. Song, H. W. Lee, and Y.-K. Kim, "Effects of high-resolution land cover and topography on local circulations in two different coastal regions of Korea: a numerical modeling study," Meteorology \& Atmospheric Physics, vol. 118, no. 1-2, pp. 1-20, 2012.

[14] A. Kumar, F. Chen, M. Barlage, M. B. Ek, and D. Niyogi, "Assessing impacts of integrating MODIS vegetation data in the weather research and forecasting (WRF) model coupled to two different canopy-resistance approaches," Journal of Applied Meteorology and Climatology, vol. 53, no. 6, pp. 1362-1380, 2014.

[15] Y. Li, J. Fan, Z. Hu, Q. Shao, L. Zhang, and H. Yu, "Influence of land use patterns on evapotranspiration and its components in a temperate grassland ecosystem," Advances in Meteorology, vol. 2015, Article ID 452603, 12 pages, 2015.

[16] X. Li, G. Cheng, S. Liu et al., "Heihe watershed allied telemetry experimental research (HiWater): scientific objectives and experimental design," Bulletin of the American Meteorological Society, vol. 94, no. 8, pp. 1145-1160, 2013.

[17] S. M. Liu, Z. W. Xu, W. Z. Wang et al., "A comparison of eddycovariance and large aperture scintillometer measurements with respect to the energy balance closure problem," Hydrology \& Earth System Sciences, vol. 15, no. 4, pp. 1291-1306, 2011.

[18] P. A. Jiménez and J. Dudhia, "Improving the representation of resolved and unresolved topographic effects on surface 
wind in the WRF model," Journal of Applied Meteorology and Climatology, vol. 51, no. 2, pp. 300-316, 2012.

[19] S. Niemelä, P. Räisänen, and H. Savijärvi, "Comparison of surface radiative flux parameterizations Part I. Longwave radiation," Atmospheric Research, vol. 58, no. 1, pp. 1-18, 2001.

[20] S. Zhong, H. In, and C. Clements, "Impact of turbulence, land surface, and radiation parameterizations on simulated boundary layer properties in a coastal environment," Journal of Geophysical Research: Atmospheres, vol. 112, no. 13, Article ID D13110, pp. 125-138, 2007.

[21] Z. Cao, J. Ma, and W. R. Rouse, "Improving computation of sensible heat flux over a water surface using the variational method," Journal of Hydrometeorology, vol. 7, no. 4, pp. 678-686, 2006.

[22] Z. Cao and J. Ma, "A variational method for computation of sensible heat flux over the Arctic sea ice," Journal of Atmospheric \& Oceanic Technology, vol. 26, no. 4, pp. 838-845, 2009.

[23] Y. H. Gao, F. Chen, M. Barlage et al., "Enhancement of land surface information and its impact on atmospheric modeling in the Heihe River basin, Northwest China," Journal of Geophysical Research D: Atmospheres, vol. 113, no. 20, pp. 838-845, 2008.

[24] H. S. Chen and J. Zhou, "Impact of interannual soil moisture anomaly on simulation of extreme climate events in China," Chinese Journal of Atmospheric Sciences, 2013.

[25] T. B. Zhao and B. Cong, "Preliminary comparison and analysis between ERA-40, NCEP-2 reanalysis and observations over China," Climatic and Environmental Research, vol. 11, no. 1, pp. 14-32, 2006 (Chinese).

[26] L. Ma, T. J. Zhang, Q. X. Li, O. W. Frauenfeld, and D. Qin, "Evaluation of ERA-40, NCEP-1, and NCEP-2 reanalysis air temperatures with ground-based measurements in China," Journal of Geophysical Research: Atmospheres, vol. 113, no. 15, pp. 797-801, 2008.

[27] C. C. Ma, Y. Yu, J. J. He, X. Chen, and J. Xie, "Analyses of simulation result in loess plateau by WRF model with two reanalysis data," Plateau Meteorology, vol. 33, no. 7, pp. 698-711, 2014 (Chinese). 

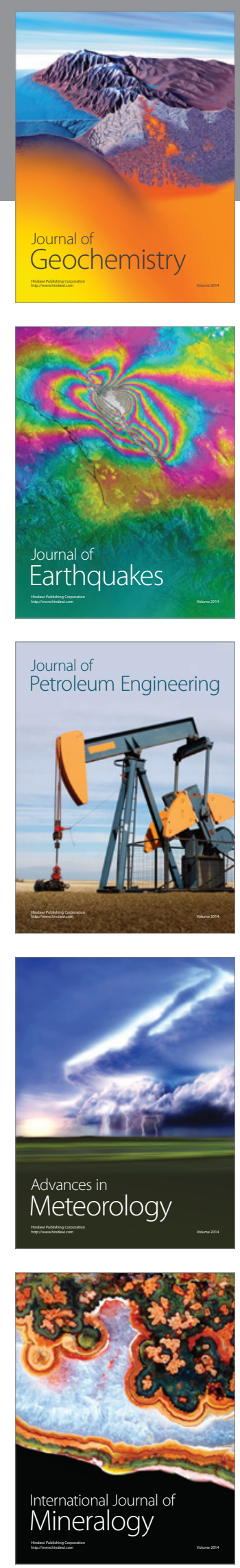
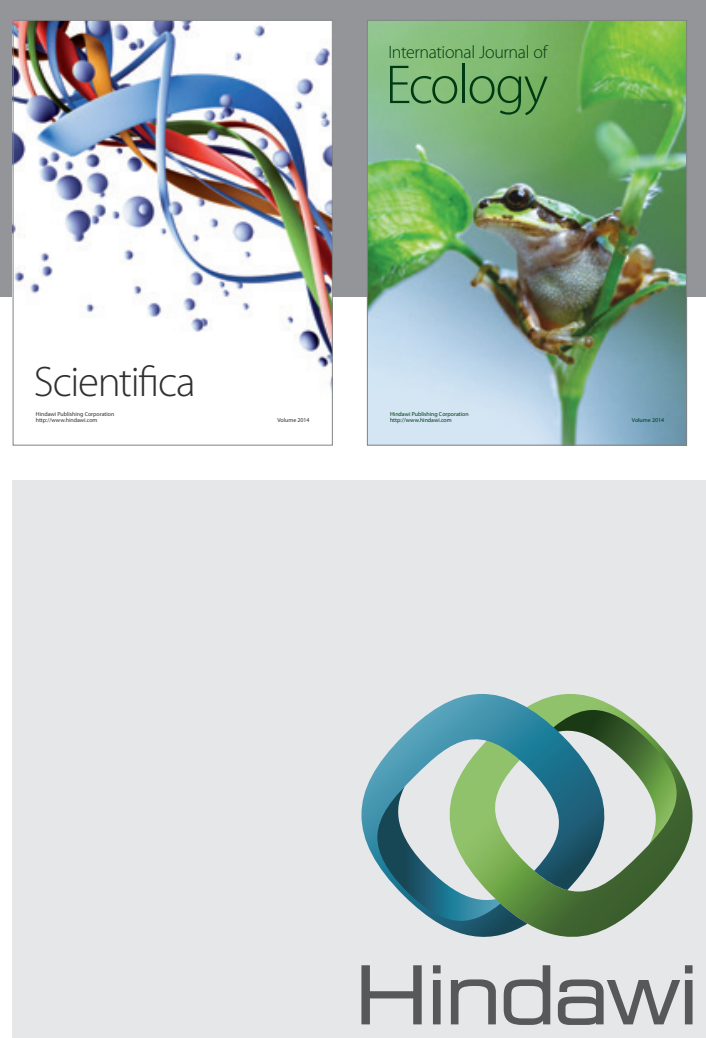

Submit your manuscripts at

http://www.hindawi.com
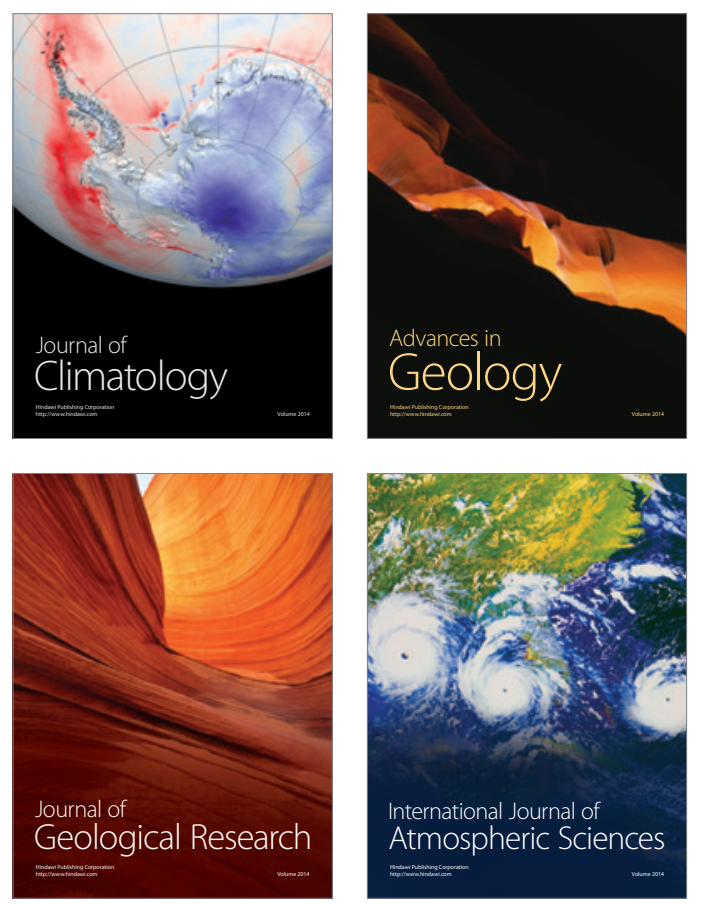

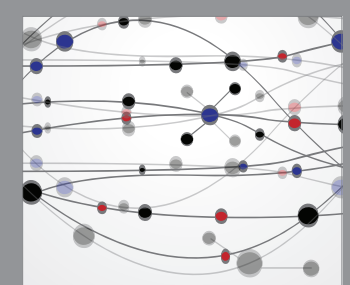

The Scientific

\section{World Journal}
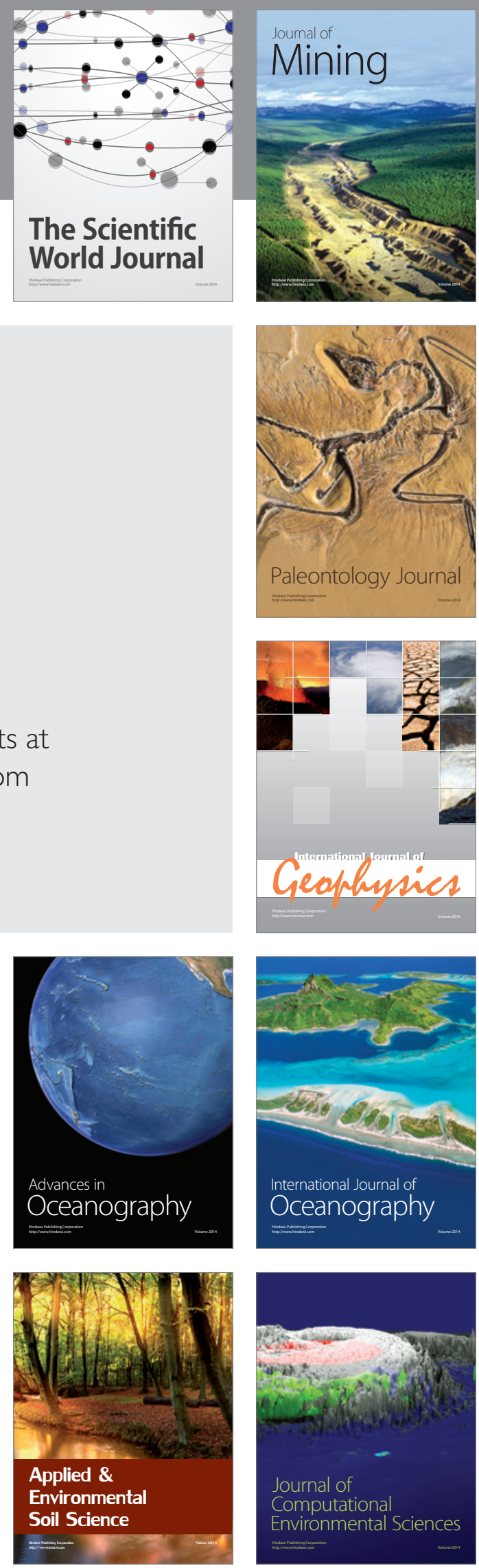